\title{
VIII. Auf der Suche nach den Konturen eines demokratischen Deutschlands: Die Analysen der Jahre 1946-1949
}

\section{Am Ende des Anfangs}

Anfang Januar 1946 hatte die inzwischen im State Department als Office of Research and Intelligence (ORI) geführte R\&A-Branch in einer ersten "Zwischenbilanz am Ende des Anfangs ${ }^{\text {" }}{ }^{1}$ versucht, die wesentlichen Elemente, Strukturen und Tendenzen der politischen und gesellschaftlichen Entwicklungen im besetzten Deutschland zu beschreiben und zu analysieren. Liest man diese Studie als Fortsetzung der von R\&A geleisteten Arbeit, so beinhaltete sie noch eine andere Art von Bilanz, da sie implizit die tatsächlichen Entwicklungen den von der Abteilung während der Kriegsjahre formulierten Erwartungen und Prognosen gegenüberstellte. Beide Bilanzen mußten für die in ORI verbliebenen R\&A-Mitarbeiter enttäuschend sein. Zwar ließen die Entwicklungen in Deutschland bald erkennen, wie berechtigt viele der in R\&A-Studien ausgesprochenen Warnungen gewesen waren, doch bedeutete diese Bestätigung eben auch, daß die Warnungen unbeachtet geblieben waren. Kaum weniger enttäuschend mußte die Erkenntnis sein, daß es weder von seiten der Deutschen noch von seiten der Besatzungsmächte Initiativen gab, einen Demokratisierungsprozeß in Gang zu setzen, der auch nur entfernt den von R\&A entwickelten Konzeptionen entsprochen hätte.

Vor diesem Hintergrund wurde die Frage, wie sich die Demokratisierung Deutschlands unter den tatsächlichen Gegebenheiten gestaltete, zum zentralen Thema der seit Anfang 1946 entstehenden ORI-Studien. Anders als die R\&A-Arbeiten der letzten beiden Kriegsjahre, die fast ausnahmslos als Beiträge zur Planung und Formulierung der amerikanischen Besatzungs- und Nachkriegspolitik intendiert gewesen waren und zumindest implizit Empfehlungen enthalten hatten, die das Engagement der Abteilung zugunsten einer an sozialistisch-sozialdemokratischen Idealen orientierten politischen und gesellschaftlichen Erneuerung Deutschlands erkennen ließen, stellten die nun entstehenden Studien eher kritisch-distanzierte Bestandsaufnahmen dar, in denen die Entwicklungen im besetzten Deutschland nüchtern als Resultat einer zwar ungleichgewichtigen, zuweilen sogar von der formalen Omnipotenz der Besatzungsmächte verdeckten, letztlich aber doch wesentlich erscheinenden Interaktion von Besatzern und Besetzten beschrieben wurden².

1 So die treffende Charakterisierung bei Borsdorf/Niethammer (Hrsg.), Zwischen Befreiung und Besatzung, S. 273; zu NA, RG 59, ORI/(R\&A) 3200, „Revival of Political Life in Germany“ vom 11.1. 1946 siehe VI., 1. Teil.

${ }^{2}$ Gesamtdarstellungen der Entwicklungen in Deutschland während der Besatzungszeit bieten z.B. Eschenburg, Jahre der Besatzung; Kleßmann, Die doppelte Staatsgründung; Benz, Von der Besatzungsherrschaft zur Bundesrepublik. Vgl. zum Folgenden auch Grabbe, Unionsparteien, Sozialdemokratie und Vereinigte Staaten, S. $77 \mathrm{ff}$. 
Wie man in ORI Charakter und Ergebnisse dieser Interaktion ein Jahr nach Kriegsende beurteilte, läßt sich vielleicht am prägnantesten mit einem Zitat aus Eugen Kogons berühmtem Artikel „Das Recht auf den politischen Irrtum“ zusammenfassen, in dem Kogon mit Blick auf die Entnazifizierung festgestellt hatte: „Deutsche Mängel und alliierte Fehler haben einander mit verhängnisvoller Sicherheit [...] ergänzt und die Anstrengungen der Einsichtigen bisher beinahe um jeden Erfolg gebracht. ${ }^{\text {"3 }}$ Auch in der Darstellung von ORI war es im wesentlichen auf „deutsche Mängel“ und „alliierte Fehler" zurückzuführen, daß sich selbst ein Jahr nach Kriegsende kaum Ansätze zu einer dauerhaften demokratischen Neuordnung erkennen ließen: „From an over-all point of view, German political life still presents an appearance of artificiality - almost unreality - notwithstanding surface appearances of intense political activity. This results particularly from (a) the survival of a Nazi or Nazi-influenced mentality in large sections of the population; (b) limited real political interest on the part of the mass of the people, especially the youth; (c) the unimaginative outlook of the traditional political parties; and (d) the fact that the decisive influence in the German situation continues to lie with the occupying powers. Under these conditions, the question of Germany's future democratic potentialities is still an open one. All German political activity necessarily remains provisional and tentative until Allied action has established the definite conditions - territorial, economic, constitutional, and ideological - under which German political life will have to operate in the future. ${ }^{\text {"4 }}$

Obwohl in der hier zitierten Passage die Auflistung der "deutschen Mängel“ mehr Raum einnimmt als die der "alliierten Fehler“, erscheinen letztere eindeutig als entscheidend für die Gesamtentwicklung. Den deutschen Anteil an der unbefriedigenden Entwicklung des ersten Nachkriegsjahres beschrieben ORI-Studien eben vor allem als „Mangel“ - als Mangel an politischem Interesse, als Mangel an Initiative, und damit implizit auch als Mangel an autochthonem demokratischen Potential' ${ }^{5}$. Nur bedingt war man in ORI bereit, dies mit den politischen und sozialen Verhältnissen der unmittelbaren Nachkriegszeit zu entschuldigen. Für die politische Apathie der Mehrheit der Bevölkerung zeigte man insofern ein gewisses Verständnis, als konzediert wurde, "[that] the daily problems of food, shelter, transportation, and work require such tremendous effort that little energy is left for politics“. Für bedenklich hielt man es freilich, daß auch die Mehrheit der Jugendlichen in Deutschland in einem „political coma“ zu verharren schien - „unmoved by general promises, preoccupied with problems of physical survival, and susceptible to extreme solutions of their present dilemma"6. Man war sich jedoch nicht sicher, ob dies als Apathie oder aber als bewußte Ablehnung der Politik zu deuten sei.

${ }^{3}$ Kogon, Das Recht auf den politischen Irrtum, in: Frankfurter Hefte 2/1947, wieder abgedruckt in ders., Die unvollendete Erneuerung, S. 23-40, Zitat S. 23.

${ }^{4}$ NA, RG 59, ORI/(R\&A) 3736, "The Political Situation in Germany a Year after Defeat", 25.6. 1946, in deutscher Übertragung gekürzt bei Söllner (Hrsg.), Archäologie der Demokratie, Bd.2, S. 67-101; die folgenden Zitate, wenn nicht anders ausgewiesen, aus dieser Studie; vgl. auBerdem die inhaltlich ähnliche, in ihren Beurteilungen bzw. in deren Formulierung aber etwas zurückhaltendere Arbeit NA, RG 59 ORI/(R\&A) 3763 A, "Contribution to the Department of State Quarterly Policy Paper: Germany“, 11.6. 1946.

5 Vgl. dazu auch Merritt/Merritt (Hrsg.), Public Opinion in Occupied Germany.

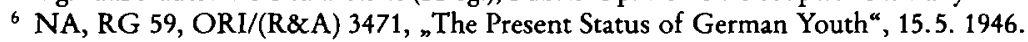


In diesem Zusammenhang wurde die Rolle der Parteien überaus kritisch gesehen. Angesichts der weitverbreiteten A pathie falle den Parteien im politischen Leben eine monopolartige Stellung zu, die sie nach Ansicht von ORI jedoch in keiner Weise zu nutzen verstanden, da sie sich unfähig zeigten, den einschneidenden Veränderungen, die seit 1933 in Deutschland stattgefunden hatten, Rechnung zu tragen. Alle Parteien, einschließlich der neu gegründeten CDU, würden von Funktionären und Politikern kontrolliert, die schon vor 1933 aktiv gewesen seien. Mit Ausnahme der Kommunisten hätten die Parteien weder ihre politische Programmatik noch ihre Strategien wesentlich verändert. So sei die CDU „little more than a revival of the Center Party as it existed under the Empire and the Weimar Republic: a heterogeneous group, aligned with the Left or with the Right according to the changing political situation"; die SPD sei weiterhin „a non-militant, pseudo-socialist party, aspiring to a position similar to that of the British Labor Party, but unlikely to succeed in mustering a like nationwide parliamentary majority."

Trotz dieser überaus kritischen Beurteilung konzedierte ORI, daß sich die deutschen Parteien mit beträchtlichen Schwierigkeiten und Problemen konfrontiert sähen. Daß die Parteien so wenig „Farbe“ bekannten, führte ORI nicht zuletzt darauf zurück, daß politische Zuordnungen wie Linke, Rechte oder Mitte und die mit ihnen gemeinhin assoziierten Programme an Aktualität und Relevanz verloren hätten, „[since] the main division in German politics has become one between ,Eastern' and ,Western' orientation". Insofern sah ORI die politischen Aktivitäten auf deutscher Seite vielfach als Reaktion auf die tatsächlichen oder nur eingebildeten Wünsche der Besatzungsmächte, und auch der „anämische“ Charakter des politischen Lebens in Deutschland war nach Ansicht der Abteilung ganz wesentlich als Konsequenz der totalen Niederlage und der Besatzung zu verstehen, denn, so argumentierte ORI: „Political life can flourish only when political parties are able freely to take a stand on basic political issues." Die Entscheidung dieser fundamentalen politischen Fragen sei aber den Besatzungsmächten vorbehalten, und nach Ansicht von ORI hatten diese es bislang versäumt, die Rahmenbedingungen für eine demokratische Neuordnung Deutschlands zu schaffen.

Als besonders problematisch betrachtete es ORI, daß die Alliierten ihre Besatzungspolitik ungeachtet der in Potsdam vereinbarten Grundsätze ${ }^{7}$ ganz unterschiedlich gestalteten und kaum koordinierten: „The policies of the Allied powers, while theoretically based on the principle of quadripartite cooperation, have been influenced by geographic, economic, and social differences between the four zones, by differences of approach inherent in their diverse social and economic traditions, and by differences of strategic aim. ${ }^{\text {" } 8}$

${ }^{7}$ Auf die in Potsdam vereinbarten Grundsätze zur politischen und wirtschaftlichen Behandlung Deutschlands wurde in ORI-Studien immer wieder als Maßstab bzw. offizielle Richtlinie der alliierten Besatzungspolitik Bezug genommen; vgl. dazu auch die unten ausführlicher behandelte Studie NA, RG 59, OIR/(R\&A) 4286, „Implementation of the Potsdam Declaration: Democratization and Denazification", 5.3. 1947. Zur Potsdamer Konferenz siehe FRUS, The Conference of Berlin 1945; einen knappen Überblick über die Aushandlung der zentralen Vereinbarungen in Potsdam bietet Frohn, Neutralisierung als Alternative zur Westintegration, S. 17-37; eine extreme, oft sarkastisch formulierte Interpretation, die den Alliierten grundsätzliche Unwilligkeit zur Kooperation unterstellt, findet sich bei Mee, Meeting at Potsdam.

${ }^{8} \mathrm{Vgl}$. dazu auch NA, RG 59, OCL/(R\&A) 3521.10, „The Position of France, Great Britain, and the USSR Toward Germany“, (First Draft), 12.8. 1946; siehe außerdem: Schwarz, Vom Reich zur Bundesrepublik; Schwabe, Die amerikanische Besatzungspolitik in Deutschland, in: Fischer/Moltmann/Schwabe (Hrsg.), Rußland - Deutschland - Amerika, S.311-322. 
Als wichtigstes Anliegen der amerikanischen Politik bezeichnete ORI die vollständige Entnazifizierung von Regierung, Verwaltung und Industrieführung, wobei sich letzteres, wie an anderer Stelle vermerkt wurde, ohne Veränderung bestehender gesellschaftlicher Strukturen vollziehe?. Die amerikanische Politik strebe im übrigen eine Demokratisierung "from below" an, d.h. einen von der lokalen Ebene ausgehenden, schrittweisen Aufbau demokratischer Strukturen und Institutionen unter Beteiligung aller demokratischer Parteien. Zudem befürworteten die USA eine Dezentralisierung administrativer und politischer Strukturen, wünschten aber gleichzeitig die Formulierung eines einheitlichen Wirtschaftsprogramms für ganz Deutschland. Da man sich auf letzteres mit Franzosen und Sowjets bislang nicht habe verständigen können, hätten die USA Reparationen in Form von Demontagen und Entnahmen aus laufender Produktion ausgesetzt.

Mit Blick auf die britische Politik stellte ORI fest, „[that] industrial revival and continuity in the administration of government and business have taken precedence over the purge of Nazi elements". Die Briten setzten sich zwar ebenfalls für eine Demokratisierung "von unten " ein und hätten ein breites Spektrum politischer Parteien zugelassen, zeigten aber nach Ansicht von ORI "an obvious preference for the relatively conservative Social Democrats".

Die französische Politik sei vor allem von unmittelbaren Sicherheitsinteressen bestimmt. Frankreich habe sich bislang jeglicher Zentralisierung im administrativen und wirtschaftlichen Bereich entgegengestellt und sei im übrigen vor allem bestrebt, sich ein Maximum an Reparationen und Wiedergutmachung zu sichern, wobei man allerdings versuche, die Wirtschaft von Gebieten, deren Anschluß an Frankreich angestrebt werde, nicht zu schädigen.

Als wichtigste Ziele der Sowjetunion bezeichnete ORI die Entnahme von Reparationen durch den Transfer von Produktionsanlagen und Kapital, und - wie eher vage formuliert wurde - den Aufbau von Strukturen in der eigenen Besatzungszone, "which will afford guarantees against Germany's again becoming a source of aggression against the Soviet Union“. Im Rahmen dieser Politik sei die Bodenreform durchgeführt worden, außerdem seien bestimmte Industrien verstaatlicht worden, um die Macht traditionell konservativer Elemente zu zerstören. Im Gegensatz zu Großbritannien und den USA strebe die Sowjetunion eine Demokratisierung "from top down" an und unterstütze die Kommunistische Partei bzw. die neu gebildete SED ,as the main implement of Soviet policy".

Angesichts dieser disparaten politischen Konzeptionen und Interessen war die Instanz, die geschaffen worden war, um zumindest ein gewisses $\mathrm{Maß}$ an interalliierter Koordination und Kooperation zu gewährleisten - der Alliierte Kontrollrat - meist nicht in der Lage, die für seine Beschlußfähigkeit notwendige Einstimmigkeit herzustellen. Nach Darstellung von ORI wurde die Arbeit des Kontrollrats vor allem durch Frankreich und die Sowjetunion behindert - Frankreich wolle der Einrichtung zentraler Behörden nicht zustimmen, solange die Rhein-Ruhr-Frage nicht geregelt war, und die Sowjetunion fürchte jegliche Beschneidung ihrer ausschließlichen Kontrolle der östlichen Besatzungszone, solange ihr Reparationsprogramm nicht abge-

\footnotetext{
9 NA, RG 59, ORI/(R\&A) 3763 A, "Contribution to the Department of State Quarterly Policy Paper: Germany“, 11.6. 1946.
} 
schlossen sei. So resümierte die Abteilung ein Jahr nach Kriegsende eine Entwicklung, vor der R\&A schon im September 1943 gewarnt hatte ${ }^{10}$ : "These differences of approach on the part of the occupation powers have led to wide variations in the status of economic reconstruction, democratization of government, administrative centralization or decentralization, political parties, and reeducation in the several zones."

Nach Ansicht von ORI prägten sich diese Unterschiede zunehmend schärfer aus, wobei nach Darstellung der Abteilung besonders die Kluft zwischen den Verhältnissen in den westlichen Besatzungszonen einerseits und der sowjetischen Besatzungszone andererseits immer deutlicher hervortrat. Diese schon geradezu gegensätzliche Entwicklung, so warnte ORI bereits zu diesem Zeitpunkt, "may well be leading toward a de facto partition of Germany even while its legal unity is maintained" ${ }^{\text {"11. Immer wie- }}$ der wurde in den Arbeiten der Abteilung darauf verwiesen, „[that the] developments in Germany under military occupation cannot fail to leave a deep impress upon the fu-

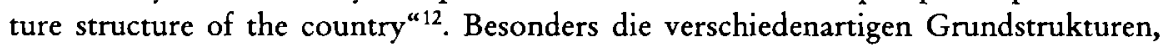
die sich als Ergebnis der von den Besatzungsmächten nach jeweils eigenem Gutdünken betriebenen Politik beim Aufbau der Parteien sowie bei der Reorganisation von Regierung und Verwaltung ausbildeten, mußten sich nach Ansicht der Abteilung letztlich als „obstacles to the maintenance of German unity “ erweisen ${ }^{13}$. Bei allen Unterschieden, die ORI auch zwischen den drei westlichen Zonen feststellte, erschien als schärfste Trennungslinie doch immer die Grenze zur sowjetischen Besatzungszone.

Wie unterschiedlich die Weichen für die politischen und gesellschaftlichen Entwicklungen im West- und Ostteil des besetzten Deutschlands bereits gestellt waren, hatte ORI in einer Studie zu „Status and Prospects of German Trade-Unions and Works Councils " 14 herausgearbeitet. Gemeinsamer Ausgangspunkt der in diesem Bereich schon ein Jahr nach Kriegsende völlig verschieden verlaufenden Entwicklungen war nach Darstellung der Abteilung das spontane Wiederaufleben der Gewerkschaftsbewegung nach dem Zusammenbruch des NS-Regimes. Daß die Aktivitäten der Gewerkschaftsausschüsse und Betriebsräte bald eine radikale politische Richtung annahmen, habe allerdings auch bald dazu geführt, „[that they came] into conflict both with MG and with the old ruling groups, which were striving to retain their economic posi-

${ }^{10}$ NA, RG 226, E 1, b 1, f 8, "Military Occupation and International Control of Germany“, 22.9. 1943 (USSR Division, G. T. Robinson an William Langer), siehe dazu V., 2. Teil.

${ }^{11}$ NA, RG 59, ORI/(R\&A) 3763 A, „Contribution to the Department of State Quarterly Policy Paper: Germany" , 11.6. 1946; Hervorhebung im Text.

12 NA, RG 59, OCL/(R\&A) 3521.12, Intelligence Memorandum (First Draft): „Current Political Tendencies in Germany Bearing on Its Future Governmental Structure", 12.8. 1946.

${ }^{13}$ NA, RG 59, ORI/(R\&A) 3401, „Reorganization of Government and Administration in Germany“, 1.5. 1946.

${ }^{14}$ NA, RG 59, ORI/(R\&A) 3381, 27.5. 1946, in deutscher Übertragung gekürzt bei Söllner (Hrsg.), Archäologie der Demokratie, Bd.2, S.121-152. Kleßmann, Betriebsräte und Gewerkschaften, in: Winkler (Hrsg.), Politische Weichenstellungen, S.44-73, bietet einen knappen, mit weiterführenden Literaturhinweisen versehenen Überblick zur Gewerkschaftsentwicklung in den ersten Nachkriegsjahren und spricht auch die Frage an, inwieweit die in der Gewerkschaftsbewegung vorhandenen Strukturen und Tendenzen den Konzeptionen der Besatzungsmächte entgegenkamen oder entgegenstanden; vgl. insbesondere zu dieser Frage auch den Beitrag von Mielke, Der Wiederaufbau der Gewerkschaften, ebenda, S.74-87. Ausführlich zur amerikanischen Gewerkschaftspolitik Fichter, Besatzungsmacht und Gewerkschaften. 
tion“. Innerhalb der Gewerkschaften selbst sei daraufhin wieder der traditionelle Konflikt zwischen militanten neuen Führungspersönlichkeiten und den weniger radikalen Vertretern der alten Gewerkschaftsbürokratie aufgebrochen.

An diesem Punkt sei die unterschiedliche Politik der Besatzungsmächte zum Tragen gekommen: Während die Russen die radikale politische Ausrichtung und eine entsprechende personelle Zusammensetzung der Gewerkschaften begrüßten und förderten, befürworteten die Westmächte „a gradualist democratic policy and political neutrality“. Nach Ansicht von ORI erklärte sich diese unterschiedliche Gewerkschaftspolitik durch fundamental verschiedene Konzeptionen antifaschistischer Politik. Die Westmächte strebten eine allmähliche Einführung demokratischer Strukturen von der Basis her an und wünschten einen möglichst geringen Grad an Zentralisierung; zudem betrachteten sie Gewerkschaften in erster Linie als wirtschaftliche Interessenvertretungen. Die Sowjets dagegen betonten das politische Versagen der Gewerkschaften und argumentierten, daß sich die gespaltene, mehrheitlich unter sozialdemokratischer Führung stehende deutsche Gewerkschaftsbewegung als unfähig erwiesen hätte, den Nationalsozialisten wirksamen Widerstand zu bieten, und sie vertraten deshalb den Standpunkt, daß die angestrebte Eliminierung der „reactionary and antidemocratic forces in Germany" die Schaffung einer mächtigen, zentralisierten und politisch verläßlichen Gewerkschaftsorganisation erfordere, die überdies bereit sein müßte, ihre wirtschaftlichen Funktionen anstehenden politischen Aufgaben unterzuordnen.

Als Resultat dieser unterschiedlichen Konzeptionen sähen sich die Gewerkschaften in den westlichen Zonen sowohl in ihren politischen Aktivitäten als auch in ihrem Streben nach zentraler Organisation mehr oder minder stark eingeschränkt, während in der sowjetischen Besatzungszone bereits zonenweit der Freie Deutsche Gewerkschaftsbund als integraler Bestandteil eines neuen politischen und gesellschaftlichen Ordnungssystems begründet worden sei. Keine der beiden Entwicklungen sah man in ORI unkritisch. Schon die Feststellung, daß beide Entwicklungen in erster Linie eine Funktion der unterschiedlichen politischen Konzeptionen der Besatzungsmächte seien, beinhaltete - zumal vor dem Hintergrund der von R\&A vertretenen Forderung nach möglichst viel Freiraum für eine eigenständige Entwicklung der Gewerkschaften - implizite Kritik. Dabei entbehrte es allerdings nicht einer gewissen Ironie, daß gerade R\&A immer wieder angeregt hatte, daß sich die Besatzungsbehörden bei der Demokratisierung Deutschlands auf die Mitarbeit der organisierten Arbeiterschaft stützen sollten. Unter ganz anderen Vorzeichen und auf ganz andere Weise, als man in R\&A gehofft hatte, wurde diese Anregung nun umgesetzt, indem die Gewerkschaften - entsprechend modelliert - als Instrumente für die Realisierung der jeweiligen Demokratisierungskonzeptionen der Besatzungsmächte eingesetzt wurden.

So wies ORI die von den westlichen Besatzungsmächten vorgeblich angestrebte politische Neutralität der Gewerkschaften als „Fiktion“ zurück. Die Bevorzugung der gemäßigteren Vertreter der Gewerkschaftsbürokratie in den westlichen Zonen habe im wesentlichen sozialdemokratisch orientierte Gewerkschaften entstehen lassen, und nach Ansicht von ORI bedeutete dies in politischer Hinsicht „de facto acceptance of the existing form of society, the focus of union activity on representing the workers within the framework of this society, and thus continued adherence to a strategy of class collaboration rather than class struggle“. 
Wenn ORI erwartete, daß die Gewerkschaften in den westlichen Besatzungszonen diese politische Linie auch künftig beibehalten würden, so schien damit wieder angedeutet, daß die von den westlichen Besatzungsmächten geförderte Entwicklung eben nicht nur oktroyiert war, sondern Traditionen und Tendenzen aufnahm, die ohnehin vorhanden waren und deshalb auch Bestand haben würden, wenn die Restriktionen der Besatzungszeit entfielen. ORI entwarf in diesem Zusammenhang ein recht zutreffendes Bild der künftigen Entwicklungen: „With the progress of political self-administration and economic reconstruction, in which Social Democrats and Christian Democrats are likely to play the leading part in the western zones, such a trade-union movement would be connected politically with an administration endeavoring to incorporate the working class into a democratic capitalist system. The situation of the trade-unions would thus be similar to that existing under the Weimar Republic. The Social Democratic conception of trade-unionism would direct union strategy to the gradual democratization of existing economic institutions and relations through increased government control over the economy, nationalization on a limited scale, and participation of labor in management."

In der sowjetischen Zone habe man dagegen das Konzept der politischen Neutralität der Gewerkschaftsbewegung ausdrücklich zurückgewiesen ${ }^{15}$ und betrachte die Gewerkschaften als integralen Bestandteil der politischen Arbeiterbewegung, die durch die SED repräsentiert sei. Sowohl die Gewerkschaften wie die Partei strebten den Aufbau einer sozialistischen Gesellschaft an; solange diese allerdings nicht verwirklicht sei, bildeten die Gewerkschaften die Massenbasis für die Ausübung unangefochtener Führung durch die Partei. Die SED bestimme die politischen Ziele und Strategien, bei ihr liege die politische Führung, während es die Aufgabe der Gewerkschaften sei, „to educate the working masses along approved lines [... and] to fulfill the ordinary needs arising from their employment status". $\mathrm{Da}$ sich die unmittelbaren Interessen der Arbeiter und die an langfristigen Überlegungen orientierten Forderungen der politischen Führung nicht immer miteinander vereinbaren ließen, müßte die politische Führung von Fall zu Fall entscheiden, ob die Erhaltung des "good will“ der Gewerkschaftsmitglieder oder die Erfüllung von Produktionsquoten wichtiger sei. Nicht ohne spöttischen Unterton bemerkte ORI, daß es vom Ergebnis dieser Entscheidung abhinge, "[if] the union leaders will [...] have to redouble their efforts at ,educating the membership [or if] they will be able to remind the workers of the gains achieved with respect to wages and hours". In Anbetracht der bisher entwickelten Konzeptionen und Strukturen könnten die Gewerkschaften keinen von den anderen politischen und administrativen Institutionen der sowjetischen Besatzungszone unabhängigen Kurs verfolgen, denn, wie ORI abschließend bemerkte: „As an integral part of the new social fabric, the unions move at the same rate as the others in the direction of a centralized socialist society."

So ließ die Entwicklung der Gewerkschaften nach Darstellung von ORI schon ein Jahr nach Kriegsende eine Weichenstellung für die Ausprägung zweier gegensätzlicher politischer und gesellschaftlicher Systeme in Deutschland erkennen: Im Westen deutete sich die Ausbildung eines „democratic capitalist system“ an, im Osten zeichnete

15 ORI illustrierte dies mit einem Zitat aus Walter Ulbrichts „Neue Aufgaben der freien Gewerk-

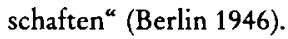


sich der Aufbau einer "centralized socialist society“ ab. Im Westen wie im Osten war diese Entwicklung - ebenso wie die entsprechende Prägung des Wiederaufbaus der Gewerkschaften - nach Darstellung von ORI in erster Linie eine Funktion der unterschiedlichen bzw. gegensätzlichen politischen Konzeptionen, Strategien und „Weltanschauungen“ der Besatzungsmächte, die sich als unfähig erwiesen, die von ihnen in Potsdam vereinbarten Grundsätze zum Ausgangspunkt einer einheitlichen Deutschlandpolitik zu machen. Die statt dessen von jeder Besatzungsmacht nach eigenem Gutdünken betriebene Politik führte nach Darstellung von ORI dazu, daß aus den Maßnahmen zu Entnazifizierung und Demokratisierung sowie der Reorganisation von Wirtschaft und Verwaltung keine Grundlage für eine umfassende politische und gesellschaftliche Erneuerung Deutschlands erwuchs, sondern lediglich eine oft künstliche

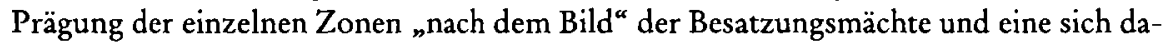
bei zunehmend ausprägende Auseinanderentwicklung der Ostzone und der Westzonen.

Insofern mochte der Eindruck entstehen, daß die Abteilung das in Besatzungszonen aufgeteilte Deutschland als bloßes Objekt alliierter Politik sah. Doch schon den von R\&A im Auftrag des War Department ausgearbeiteten Papieren hatte stets die Überzeugung zugrunde gelegen, daß sich die Militärregierung in Deutschland aus pragmatischen wie politischen Überlegungen auf die Mitarbeit von Deutschen würde stützen müssen und daß diese - auch wenn sie zunächst nicht viel mehr als Befehlsempfänger sein mochten - angesichts der Komplexität der zu bewältigenden Aufgaben bald einen gewissen Handlungsspielraum und damit Möglichkeiten der Einflußnahme erlangen würden. Es war wohl diese Vorstellung von der „begrenzten“ Macht der formal über absolute Befehlsgewalt verfügenden Militärregierung, die dann die in Deutschland stationierten R\&A-Mitarbeiter früh nach den politischen Tendenzen der „Zusammenbruchgesellschaft" hatte fragen lassen. Obwohl die R\&A-Mitarbeiter angesichts der von der Abteilung formulierten Hoffnungen und Erwartungen kaum unvoreingenommen an die Beantwortung dieser Frage gehen konnten, zeigten sie in ihren Berichten aus Deutschland doch wenig Neigung, die Bedeutung der Entwicklungen, die - wie vor allem die "Antifas" - ihren Hoffnungen und Erwartungen entsprachen, zu überschätzen.

Konsequent erscheinen dann auch in dem von ORI gezeichneten Bild der Entwicklungen des ersten Nachkriegsjahres deutsche „Mängel“ als wesentlicher Faktor. Sowohl in der Zwischenbilanz zum „Revival of Political Life" vom Januar 1946 wie in der Bestandsaufnahme zur "Political Situation in Germany a Year after Defeat" vom Juni und in der Gewerkschaftsanalyse vom Mai beschreibt ORI eine Bevölkerung, die in ihrer Mehrheit den Bruch mit Denk- und Verhaltensmustern der NS-Zeit nicht vollzogen hat und sich - wie verständlich angesichts der existentiellen Notlage und der schwierigen Lebensbedingungen der unmittelbaren Nachkriegszeit auch immer - politisch weitgehend desinteressiert zeigt; Parteien, die phantasielos und politisch wenig kreativ nur den Rückgriff auf Programme, Strukturen und Strategien der Weimarer Zeit anzubieten haben und über neue Ansätze und Lösungen kaum nachzudenken scheinen, mithin den Vorgaben der Militärregierungen auch wenig entgegenzusetzen haben; und schließlich eine Arbeiterbewegung, die trotz verheißungsvoller Anfänge aus der Unterdrückung und Verfolgung der vergangenen zwölf Jahre keine tragfähige Einheit entwickelt hat und deren traditionelle Spaltung den Besatzungsmächten Ansätze bietet, sie für ihre gegensätzlichen Konzeptionen zu instrumentalisieren. 
Diese gegensätzlichen Konzeptionen der beiden Großmächte erscheinen in der Darstellung von ORI zunächst insofern als gleichberechtigte Alternativen, als beide letztlich als aus eigenen Traditionen erwachsend und durch eigene Interessen motiviert erklärt werden und zudem mit Blick auf das „Objekt“ der jeweiligen Politik - Deutschland eben nicht nur per Oktroi durchgesetzt werden, sondern an bereits vorhandene Tendenzen anknüpfen und sich mit den entsprechenden politischen Kräften „verbünden“ bzw. diese instrumentalisieren können. Grundsätzlich mußte ORI diese Instrumentalisierung hüben wie drüben ablehnen, da sie die autochthone Demokratisierung, auf die R\&A gehofft hatte und die R\&A für notwendig gehalten hatte, be- oder verhinderte. Legt man die während der letzten beiden Kriegsjahre formulierten Erwartungen und Empfehlungen zugrunde, so hatte sich die sowjetische Besatzungsmacht zwar sozusagen mit den "richtigen" politischen und gesellschaftlichen Kräften "verbündet", doch entsprach nicht nur deren unverzügliche Instrumentalisierung den von der Abteilung vertretenen Demokratisierungskonzeptionen wenig. Problematisch mußte dieses „Bündnis“ in den Augen der Abteilung auch dadurch werden, daß diese Kräfte weder die notwendige politische Energie noch Konzeptionen und Strategien entwickelt hatten, die sie zum gewissermaßen legitimen Motor einer Demokratisierung hätten machen können. Tatsächlich schien sich für die von der sowjetischen Besatzungsmacht verordnete „social revolution" keine demokratische Mehrheit gewinnen zu lassen: Wie ORI konstatierte, zeigten die Ergebnisse der ersten Wahlen in der sowjetischen Besatzungszone die ungebrochene Stärke der antisozialistischen bürgerlichen Mittelschichten ${ }^{16}$. Andererseits schien nach Darstellung der Abteilung die von den westlichen Besatzungsmächten in Gang gesetzte Entwicklung, die im wesentlichen als „Restauration“ des Status quo ante beschrieben wurde, von einer Mehrheit der Deutschen gebilligt zu werden ${ }^{17}$ : Fast schon enttäuscht verzeichnete ORI, daß sich die in der amerikanischen Zone abgehaltenen Gemeindewahlen sowie die dort bereits initiierte Ausarbeitung von Verfassungsentwürfen - „despite the democratic character of these procedures " - meist "in a conservative direction" entwickelt hätten. ${ }^{18}$ Der in dieser Beurteilung angedeutete Gegensatz zwischen „democratic" und "conservative" mochte noch einmal die politischen Wunschvorstellungen der Abteilung verraten, doch in zunehmendem Maße schien sich ORI damit abzufinden, daß die Art von Demokratisierung, auf die R\&A gehofft hatte, in Deutschland nicht „mehrheitsfähig“ war. Zwar mochte man die Entwicklungen in den westlichen Besatzungszonen immer noch als versäumte Neuordnung betrachten, doch schien man ihre Interpretation als „verhinderte Neuordnung " nicht für gerechtfertigt zu halten ${ }^{19}$. Vor die-

${ }^{16}$ NA, RG 59, OCL [ORI wurde inzwischen als Office of Intelligence Coordination and Liaison geführt, siehe dazu Kapitel VII.]/(R\&A) 4152, „Controversial Issues in German Policy Raised by Secretary Byrnes' Stuttgart Speech“, 24.9. 1946.

${ }^{17}$ Petersons Auseinandersetzung mit der Kritik amerikanischer Linksliberaler an der US-Besatzungspolitik dürfte die Sicht von ORI wohl treffend beschreiben: „reaction meant going back not to Nazi, but pre-Nazi practices, and the reaction was democratic in that the people voted for it"; ders., American Occupation, S. 351.

18 NA, RG 59, ORI/(R\&A) 3763 A, "Contribution to the Department of State Quarterly Policy Paper: Germany“, 11.6. 1946.

19 Schmidt, Die verhinderte Neuordnung 1945-1952. Interessant sind in diesem Zusammenhang die Überlegungen von Löwenthal, The „Missing Revolution“, in: Berghahn/Kitchen (Hrsg.), Germany in the Age of Total War, S. 240-257. 
sem Hintergrund wich die anfänglich weitgehend unparteiische Darstellung der von den USA und der Sowjetunion verfolgten Politik als im wesentlichen gleichberechtigter Alternativen allmählich einer Sichtweise, in der das Attribut „demokratisch“ - wenn auch meist in einem gewissermaßen rein verfahrenstechnischen Sinn - immer mehr der amerikanischen Politik vorbehalten wurde.

In diesem Sinne erschienen die Amerikaner auch mit Blick auf die Entwicklungen in den westlichen Zonen als die „besten“ Demokraten. Früher als Briten und Franzosen begannen sie mit der Reorganisation der Länder in ihrer Zone und leiteten die schrittweise Übertragung verwaltungsmäßiger Zuständigkeiten an deutsche Behörden ein ${ }^{20}$. Bereits im Herbst 1945 hatte das neugegründete Office of Military Government (OMGUS) unter Leitung von General Lucius D. Clay ${ }^{21}$ die Einrichtung der drei Länder Groß-Hessen, Bayern und Württemberg-Baden vorbereitet und mit der Einsetzung des aus den drei Ministerpräsidenten bestehenden Länderrats zugleich ein zonales Koordinationsgremium geschaffen, das ein Umschlagen der Politik der einzelnen Länder von dem gewünschten Föderalismus in einen nicht intendierten Partikularismus oder Separatismus verhindern konnte. Nachdem Ende Januar 1946 Gemeindewahlen in der US-Zone abgehalten worden waren, erhielten die Ministerpräsidenten der drei Länder im Februar den Auftrag, die Ausarbeitung von Länderverfassungen vorzubereiten, womit nach Ansicht von ORI „a process of formal democratization“ initiiert worden war 22 .

Dessen Verlauf und Entwicklung betrachtete man in der Abteilung angesichts der konservativen Tendenzen, die man zu beobachten glaubte, freilich mit Skepsis ${ }^{23}$. Interessanterweise hielt es ORI jedoch für angebracht, den von der Abteilung formulierten "Comments on the Draft Constitutions" die fast schon rechtfertigende Bemerkung voranzustellen, daß es angebracht sei zu überprüfen, inwieweit die in den Verfassungsentwürfen vorgesehenen Bestimmungen mit den erklärten Grundsätzen und Zielen alliierter bzw. amerikanischer Politik vereinbar waren ${ }^{24}$. Besonderes Augenmerk habe überdies den Bestimmungen zu gelten, die sich mit der Absicherung der Grundrechte und demokratischer Institutionen sowie der Regelung des Verhältnisses zwischen Ländern und Zentralregierung befaßten.

In allen Entwürfen vermißte ORI einen Hinweis auf die vorläufig noch gegebene Prärogative der Besatzungsmacht und empfahl die Einfügung entsprechender Klauseln. Abgesehen von dieser grundsätzlichen Kritik fand die Abteilung an dem von Groß-Hessen vorgelegten Entwurf am wenigsten auszusetzen. Obwohl er in Einzel-

${ }^{20}$ NA, RG 59, ORI/(R\&A) 3401, „Reorganization of Government and Administration in Germany", 1.5. 1946.

${ }^{21} \mathrm{Zu}$ der von Zeitgenossen und Historikern kontrovers beurteilten Rolle Clays Krieger, General Lucius D. Clay, und Backer, Winds of History (Die deutschen Jahre des Generals Clay).

22 NA, RG 59, ORI/(R\&A) 3401, "Reorganization of Government and Administration in Germany", 1.5. 1946.

${ }^{23}$ Dazu und zum Folgenden NA, RG 59, OCL/(R\&A) 3521.13: „Comments on the Draft Constitutions for the Three States in the US Zone of Germany“, 19.8. 1946.

$24 \mathrm{Vgl}$. in diesem Zusammenhang Birke, Die aufgezwungene Demokratie?, in: Heideking/Hufnagel/Knipping (Hrsg.), Wege in die Zeitgeschichte, S. 151-163; sowie Fait, „In einer Atmosphäre von Freiheit“, in: VfZ 33 (1985), S.420-455; vgl. außerdem den Überblick bei Eschenburg, Jahre der Besatzung, S. 242-262. 
heiten verbesserungsbedürftig sei, bezeichnete ihn ORI nach Kriterien offizieller USPolitik als den am zufriedenststellendsten und sowohl dem württemberg-badischen wie dem bayerischen eindeutig überlegen.

An dem von Württemberg-Baden vorgelegten Entwurf kritisierte ORI eine zu weitgehende Orientierung an der Verfassung von Weimar, denn nach Ansicht der Abteilung hatten die württemberg-badischen Verfassungsväter auch manche der Schwächen ihrer Vorlage übernommen. So fand es ORI bedenklich, daß die Stellung des vorgesehenen Staatspräsidenten gar explizit als „being above the powers" definiert wurde, da tatsächlich die Gefahr bestehe, daß diese Macht mißbraucht würde. Im übrigen lehnte ORI die im Entwurf vorgesehene Zweite Kammer ab und schlug vor, die Macht des Parlaments eher nach dem Vorbild des groß-hessischen Verfassungsentwurfs zu beschränken und etwa Bestimmungen aufzunehmen, die für ein Mißtrauensvotum eine absolute Mehrheit erforderlich machten. Außerdem hatte ORI Einwände gegen Formulierungen im Bereich der Grundrechte, da sie ähnlich wie in der Weimarer Verfassung keine ausreichende Absicherung gegenüber der Legislative garantierten. Die Bestimmungen des Entwurfs zur Außenpolitik waren nach Ansicht der Abteilung völlig überflüssig, da diese in den Kompetenzbereich einer künftigen Reichsregierung falle. Wie ORI nicht ohne Ironie meinte, sei es insofern „probably unnecessary for Württemberg-Baden to ,renounce war as an instrument of policy" ".

Der bayerische Entwurf - dessen Text der Abteilung allerdings nicht vorlag, so daß sich die Kritik auf Informationen aus der Presse stützte - wurde als völlig unbefriedigend zurückgewiesen. Kategorisch lehnte ORI alle auf einen bayerischen Freistaat abzielenden Ambitionen ab und sah daher keine Notwendigkeit, eine bayerische Staatsbürgerschaft oder bayerische Außenpolitik zu diskutieren. Statt dessen forderte die Abteilung, daß Bayerns Status als Mitgliedsstaat des künftigen Deutschlands, dessen Verfassung Vorrang vor den Länderverfassungen haben würde, eindeutig festzulegen sei. Die im bayerischen Verfassungsentwurf entwickelten Vorstellungen von einem dem Schweizer Modell folgenden System einer auf vier Jahre fest gewählten Regierung erachtete ORI für Deutschland als geradezu gefährlich, da dadurch "Hitler-Karrieren" begünstigt würden. Ohne Rücksicht auf bayerische Sensitivitäten forderte ORI, „[that the] system should be replaced by a parliamentary structure on the model of the Greater Hesse draft".

Grundsätzlich sei, so resümierte ORI, an allen Entwürfen zu kritisieren, „[that they] allow unduly wide scope for the exercise of emergency powers by the executive, make inadequate provisions for the safeguarding of fundamental rights, and suffer from the prevalence of bombastic and diffuse language“. Die von den drei Ländern der amerikanischen Zone vorgelegten Verfassungsentwürfe dürften mithin wenig geeignet gewesen sein, die Skepsis der Abteilung gegenüber deutschen Vorstellungen von Demokratisierung zu beschwichtigen ${ }^{25}$. Allerdings stand ORI mit dieser Skepsis keineswegs allein: Die OMGUS-Abteilungen, die die Verfassungsentwürfe kommentierten, fanden ebenfalls zahlreiche Kritikpunkte, und auch im War Depart-

25 Die Bilanz zur „Implementation of the Potsdam Declaration: Democratization and Denazification“, 5.3. 1947 (NA, RG 59, OIR/((R\&A)) 4286, s.u.), enthielt dann auch ein Kapitel zu „Democratic and Undemocratic Features of the Constitutions“. 
ment sah man sich veranlaßt, eine lange Liste mit Änderungswünschen zu formulieren $^{26}$.

Ungeachtet der sich in dieser Kritik ausdrückenden Zweifel an der demokratischen „Reife“ der Deutschen begann sich seit Mitte 1946 in Washington aber die Überzeugung durchzusetzen, daß die amerikanische Deutschlandpolitik angesichts des bisherigen Scheiterns der interalliierten Kooperation und der infolgedessen ungelösten Probleme in eine neue Phase eintreten müßte. Wie ein ORI-Bericht im Juni konstatierte, verspürten sowohl die USA wie auch Großbritannien in Anbetracht der Hartnäckigkeit, mit der Franzosen und Russen die Regelung zentraler Probleme im Alliierten Kontrollrat blockierten, ,an increasing disinclination further to complicate the difficulties of the situation by pressing enforcement of the negative clauses of Potsdam (reparations and deindustrialization) unless the clauses about treatment of Germany as an economic unit are also enforced“27.

Tatsächlich hatte General Clay bereits Anfang Mai die vorläufige Aussetzung von Demontagen in der US-Zone angeordnet ${ }^{28}$. Immer wieder hatte Clay die Washingtoner „decision makers“ gedrängt, Schritte zur Durchsetzung der in Potsdam vereinbarten Behandlung Deutschlands als wirtschaftlicher Einheit zu unternehmen, und im Mai hatte er in einem Bericht an das War Department sogar die Schaffung einer provisorischen deutschen Zentralregierung vorgeschlagen ${ }^{29}$. Während man in Washington nicht so weit gehen wollte, signalisierte Byrnes mit seiner auf der Pariser Konferenz des Rats der Außenminister im Juli 1946 vorgetragenen Initiative für einen wirtschaftlichen Zusammenschluß der Besatzungszonen doch, daß die USA entschlossen waren, die wirtschaftliche Einheit Deutschlands nun ohne Rücksicht auf französische oder russische Obstruktion zu forcieren $^{30}$. Das bedeutete freilich auch, daß man bereit war, notfalls eine Vertiefung der Spaltung Deutschlands in Kauf zu nehmen, denn schließlich stand kaum zu erwarten, daß die von Byrnes ausgesprochene „Einladung“ zu einem wirtschaftlichen Zusammenschluß der Zonen von russischer oder französischer Seite plötzlich vorbehaltslos begrüßt würde. Nachdem tatsächlich nur die Briten dem amerikanischen Vorschlag folgten, begannen im Sommer 1946 die Vorbereitungen für die Einrichtung der „Bizone ${ }^{u 31}$.

Vor diesem Hintergrund wurde im State Department Ende Juli eine eigens eingerichtete Arbeitsgruppe beauftragt, eine Denkschrift über die Grundzüge der langfristigen amerikanischen Deutschlandpolitik zu entwerfen ${ }^{32}$. Zur Arbeit dieser Gruppe

${ }^{26}$ Vgl. dazu Fait, „In einer Atmosphäre von Freiheit“, VfZ 33 (1985), S.435ff.; Birke, Die aufgezwungene Demokratie?, in: Heideking/Hufnagel/Knipping (Hrsg.), Wege in die Zeitgeschichte, S. $162 \mathrm{ff}$.

${ }^{27}$ NA, RG 59, ORI/(R\&A) 3736 A, "Contribution to the Department of State Quarterly Policy Paper: Germany", 11.6. 1946.

${ }^{28}$ Siehe z. B. Krieger, General Lucius D. Clay, S. $139 \mathrm{ff}$.

${ }^{29}$ Lucius D. Clay, Entscheidung in Deutschland, S. $90 \mathrm{ff}$.

${ }^{30}$ Die Bewertung dieser Initiative und der mit ihr verbundenen Intentionen ist kontrovers, vgl. dazu Gimbel, Byrnes und die Bizone, in: Benz/Graml (Hrsg.), Aspekte deutscher Außenpolitik, S. 193-210; Frohn, Neutralisierung, S.52ff., $68 \mathrm{ff}$.

${ }^{31}$ Einzelheiten dazu bei Benz, Von der Besatzungsherrschaft zur Bundesrepublik, S. 35 ff.; vgl. außerdem Overesch, Einheit oder Teilung?, in: Foschepoth (Hrsg.), Kalter Krieg und Deutsche Frage, S. 269-290, sowie ausführlich Schwarz, Vom Reich zur Bundesrepublik, S. $299 \mathrm{ff}$.

32 Vgl. dazu Frohn, Neutralisierung, S. 38, 73 ff. Laut Frohn (S.73, Anmerkung 209; ebenso Kreikamp, Die amerikanische Deutschlandpolitik im Herbst 1946, in: VfZ 29 ((1981)), S. 269-285, 
scheint ORI eine Reihe von Studien beigesteuert zu haben, deren wesentliche Thesen und Argumentationen in einem Memorandum zum "General Character of a Future German Government ${ }^{\text {c }}$ enthalten sind ${ }^{33}$. Ausgangspunkt der in diesem Memorandum entwickelten Überlegungen war die Annahme, daß die amerikanische Politik in bezug auf eine künftige deutsche Regierung an drei „desiderata“ - nämlich „viability, stability, and democratic character" - orientiert sein würde. Das erstgenannte Desiderat, die Existenzfähigkeit einer künftigen deutschen Regierung, war nach Ansicht von ORI allerdings weniger eine Funktion des „Charakters“ der deutschen Regierung selbst, sondern vielmehr der allgemeinen Rahmenbedingungen, unter denen sie zu operieren haben würde. Insbesondere territoriale Regelungen und Bestimmungen über wirtschaftliche Restriktionen sowie die sich daraus ergebenden Konsequenzen für den Lebensstandard in Deutschland seien in diesem Zusammenhang von entscheidender Bedeutung $^{34}$.

Um die Stabilität und den demokratischen Charakter einer künftigen deutschen Regierung zu sichern, waren nach Ansicht von ORI sowohl konstitutionell-strukturelle wie politische Gesichtspunkte zu berücksichtigen. Im politischen Bereich seien vor allem zwei Faktoren von ausschlaggebender Bedeutung. Zum einen müsse eine künftige deutsche Regierung bei ihrem Amtsantritt bereits Klarheit über die Friedensbedingungen haben, da dies sowohl dem Ansehen der Regierung wie auch ihrer Fähigkeit zu planen und zu funktionieren zugute kommen würde; andernfalls sei zu befürchten, daß die Regierung als abhängig von „foreign powers" erscheinen und entsprechend Autorität einbüßen könnte. Als weiteren wichtigen politischen Faktor nannte ORI die Existenz demokratischer Parteien. Wie ausgeführt wurde, ergebe sich allerdings ein Dilemma, wenn man sowohl die Stabilität einer Regierung als auch ihren demokratischen Charakter gewährleistet sehen wollte, denn, so argumentierte die Abteilung: „Strengthening certain authoritarian parties (Communists, reactionaries) might guarantee governmental stability, but at the expense of the democratic character of government."

ORI erwartete, daß die amerikanische Politik deshalb zum einen bestrebt sein würde, auf die Verankerung stabilisierender Elemente in der Struktur einer künftigen deut-

siehe S.274f.) unterstand dieses Komitee der Leitung von James W. Riddleberger (Chief, Division of Central European Affairs); als Mitglieder nennt Frohn J. K. Galbraith (Direktor des Office of Economic Security Policy), H.P. Leverich (Mitarbeiter des Assistant Secretary of State for Public Affairs) sowie den ehemaligen R\&A-Mitarbeiter Edward S. Mason, der inzwischen als Berater des State Department fungierte.

${ }^{33}$ NA, RG 59, OCL/(R\&A) 3521.9, (First Draft): „The General Character of a Future German Government", 12.8. 1946, deutsch in Söllner (Hrsg.), Archäologie der Demokratie, Bd.2, S. 102-112. Vgl. außerdem NA, RG 59, ORI/(R\&A) 3521.6, „A Discussion of Possible Constitutional Provisions for a German Federal Government", 20.6. 1946, sowie die überarbeitete Fassung 3521.6 a vom 8.7. 1946, und NA, RG 59, OCL/(R\&A) 3521.11, „The Present German Territorial Situation“, (First Draft), 12.8. 1946, bzw. 3521.11 A, „Problems of the German Territorial Settlement “ 23.10 .1946 . Erst im Februar 1947 erschienen in dieser Serie OCL/(R\&A) 3521.17, "Allied Policies on German Banking“, 7.2. 1947, sowie OCL/(R\&A) 3521.18, "The Problem of Central Control of German Occupation Costs", 18.2. 1947.

34 Dazu NA, RG 59, OCL/(R\&A) 3521.11, "The Present German Territorial Situation“, (First Draft), 12.8. 1946, sowie die überarbeitete Fassung 3521.11 A, „Problems of the German Territorial Settlement", 23.10. 1946. 
schen Regierung hinzuwirken, und daß sie zum anderen diejenigen Parteien fördern würde, die in ihrer Struktur und ihren Programmen demokratisch seien. Nur eine der größeren Parteien entsprach nach Ansicht von ORI diesen Kriterien: „So far only one major party (the Social Democratic) has emerged which fully guarantees liberal-democratic policies in the Western sense." Die Kommunistische Partei wurde mit der Bemerkung abgetan, daß sie „obviously [...] a different concept of ,democracy“ vertrete, und an den bürgerlichen Parteien wurde kritisiert, daß sie trotz ihrer demokratischen Programme zuweilen „strongly reactionary tendencies in policies and personalities“ zeigten. Innerhalb dieser Parteien gebe es jedoch mehr oder minder deutlich hervortretende „linke Flügel“ oder „fortschrittliche Elemente“, die sich diesen Tendenzen entgegenstellten; dazu seien etwa die CDU-Verbände von Großhessen und Berlin - im Vergleich zur bayerischen CSU - zu rechnen. So resümierte ORI: „It is upon these portions of the middle-class parties and upon the Social Democratic Party (SPD), that US policy can chiefly rely for the implementation of a democratic governmental program.“

Abgesehen von diesen politischen Gesichtspunkten standen nach Ansicht von ORI vier konstitutionelle und strukturelle Fragen im Mittelpunkt der Überlegungen zur Absicherung der Stabilität und des demokratischen Charakters eines künftigen deutschen Regierungssystems: die Diskussion um einen föderalistischen oder zentralistischen Aufbau des künftigen deutschen Staates, die Frage des Wahlsystems, das Verhältnis von Legislative und Exekutive sowie die Beschränkung der staatlichen Macht durch die Garantie von Grundrechten und anderen Regelungen.

Die Bedeutung einer Dezentralisierung als Instrument der Demokratisierung wurde nach Ansicht von ORI häufig überschätzt ${ }^{35}$. Unter Verweis auf das Hohenzollernreich und die Weimarer Republik argumentierte die Abteilung: "Whether Germany has been democratic and peace-loving, or authoritarian and aggressive, has depended on the policies of its government and the character of the groups supporting it rather than upon the distribution of power between Reich and member states." Beim Aufbau einer neuen Verwaltungs- und Regierungsstruktur sei es deshalb wichtiger, das demokratische Funktionieren der Reichsregierung sicherzustellen, als sich zu sehr auf zweifelhafte regionale Autonomiebestrebungen zu verlassen. Überdies sei zu berücksichtigen, daß ein moderner Staat für sein Funktionieren ein gewisses Maß an Zentralisierung benötige, und daß dies besonders für das zerstörte Deutschland gelte, dessen Wiederaufbau sinnvoll geplant und koordiniert werden müsse. Dementsprechend plädierte ORI für ein System, in dem die wichtigsten Regierungsgewalten - insbesondere die Legislative - bei den Reichsbehörden lägen, während Aufgaben wie interne Verwaltung, Bildungswesen und Polizei den Ländern übertragen werden könnten. Die Gefahr, daß ein zentralistischer Aufbau die Ausweitung des in der sowjetischen Besatzungszone etablierten Systems mit seiner deutlichen Tendenz zur Einparteienherrschaft begünstigen könnte, sah ORI nicht gegeben. Nach Ansicht der Abteilung mußte ganz im Gegenteil in Rechnung gestellt werden, daß eine stark föderalistisch ausgeprägte Struktur angesichts der verhältnismäßig großen Zahl regionaler Einheiten in der sowjetischen

${ }^{35} \mathrm{Zu}$ diesem Thema legte die Abteilung im November eine umfassende Studie vor, in der die von den Alliierten vertretenen Positionen sowie die deutschen Tendenzen erörtert wurden: NA, RG 59, OCL/(R\&A) 3782, „Centralism and Federalism in Germany“, 1.11. 1946. 
Zone deren Gewicht unter Umständen stärker zur Geltung bringen könnte als ein eher zentralistisch geprägtes System.

Mit Blick auf das Wahlsystem sei die Kontroverse um das Verhältniswahlrecht besonders wichtig. Erneut vertrat ORI die Ansicht, daß man sich nicht zu sehr auf eine "deterministische" Sicht versteifen sollte, zumal sich das Scheitern der Weimarer Republik nicht, wie gelegentlich argumentiert würde, in erster Linie auf das Verhältniswahlrecht zurückführen ließe. Andererseits hielt ORI die Einführung des Mehrheitswahlrechts nicht für ratsam, da nicht auszuschließen sei, daß davon vor allem die Kommunisten und die konservativen Flügel der bürgerlichen Parteien profitieren könnten. Statt dessen war nach Ansicht der Abteilung ein modifiziertes Verhältniswahlrecht vorzuziehen; das Gewicht von Splitterparteien könne zudem durch die Festlegung eines notwendigen Mindestprozentsatzes an Wählerstimmen kontrolliert werden.

In der Frage, ob für Deutschland eine parlamentarische oder eine präsidiale Demokratie vorzuziehen sei, plädierte ORI - wiederum unter Verweis auf die „Lehren“ der deutschen Geschichte - entschieden für ein parlamentarisches System: „An independent executive, whether issuing from monarchical authority or from a popularly elected president, always proved fatal to democracy." Der Grund dafür sei darin zu sehen, "that the executive in Germany has traditionally headed a bureaucracy which, because of its prestige and entrenched position, tended to concentrate actual powers in itself even if formal responsibility belonged to some elected body".

Vor diesem Hintergrund hielt ORI es für besonders wichtig, daß die in der Verfassung ${ }^{36} \mathrm{zu}$ garantierenden bürgerlichen und politischen Grundrechte wie Meinungsfreiheit, Versammlungsfreiheit und Schutz vor willkürlicher Verhaftung gegen Übergriffe der Exekutive abgesichert würden. Alle Notstandsbestimmungen, die die Außerkraftsetzung dieser Grundrechte ermöglichten, sollten zeitlich eng begrenzt und zudem äußerst sorgfältig definiert werden. Wie die Entwicklungen während der Weimarer Republik gezeigt hätten, sei es darüber hinaus erforderlich, einer Aushöhlung der Grundrechte durch den Gesetzgeber einen Riegel vorzuschieben. Problematisch war nach Ansicht der Abteilung in diesem Zusammenhang die Frage, ob solche Bestimmungen zum Schutz der Grundrechte auch Eigentumsrechte einschließen sollten. Unter Verweis auf die Erfordernisse des wirtschaftlichen Wiederaufbaus argumentierte ORI, daß es kaum realistisch sei, Eingriffe durch den Gesetzgeber grundsätzlich ausschlieBen zu wollen. Ferner sei zu bedenken, daß gewisse Reformen - wie etwa die in der sowjetischen Besatzungszone durchgeführte Neuverteilung von Grund und Boden auch im Interesse einer Demokratisierung lägen ${ }^{37}$, und daß die Verstaatlichung bestimmter Industrien dementsprechend nicht nur von kommunistischer Seite gefordert, sondern auch von Sozialdemokraten und sogar den linken Flügeln der bürgerlichen

36 Überlegungen zu den Grundzügen einer künftigen deutschen Verfassung hatte ORI bereits im Juni skizziert: NA, RG 59, ORI/(R\&A) 3521.6, " A Discussion of Possible Constitutional Provisions for a German Federal Government", 20.6. 1946, überarbeitete Fassung 3521.6 a vom 8.7. 1946.

37 Vgl. dazu NA, RG 59, OCL/(R\&A) 3525.10, "Land Reform in the Soviet Zone of Germany", 5.9. 1946: "The agrarian reform, in abolishing the large estates, destroyed one of the groups which most consistently opposed any real democratization of German society"; außerdem wurde darauf verwiesen, daß diese Reform von breiten Teilen der Bevölkerung begrüßt werde und daß sich die mit Land bedachten Bauern der SED verpflichtet fühlen müßten. 
Partein befürwortet werde ${ }^{38}$. Explizit und eindringlich warnte ORI, daß ein amerikanisches Insistieren auf dem absoluten Schutz privater Eigentumsrechte die demokratischen Kräfte in Deutschland entfremden und gleichzeitig jenen konservativen bzw. reaktionären Kreisen zugute kommen würde, die ohnehin bestrebt seien, jegliche wirtschaftliche Macht für ihre politischen Zwecke zu nutzen ${ }^{39}$.

In diesem mit bemerkenswertem Engagement vorgetragenen Plädoyer scheint unverkennbar noch einmal die von R\&A entworfene Deutschlandpolitik auf, deren Ziel - ein ungeteiltes, demokratisch-sozialistisches Deutschland - inzwischen zum „dritten Weg" zwischen einem zwar im technischen Sinne demokratischen, aber kapitalistischen Westdeutschland und einem zwar sozialistischen, aber undemokratischen Ostdeutschland geworden war. Deutlich wird hier auch noch einmal, daß die von R\&A geforderte "social revolution" - die wirtschaftliche und damit auch politische Entmachtung der traditionellen Herrschaftselite - das Herzstück dieser Alternative war: Während die Stellungnahmen der Abteilung zu politischen und verfassungsrechtlichen Fragen eher verhalten formuliert sind, setzte sich ORI fast schon leidenschaftlich dafür ein, daß die amerikanische Besatzungsmacht die Deutschen nicht an einer Demokratisierung der wirtschaftlichen Machtverhältnisse hindern sollte. Damit schien sich in diesem Plädoyer die Hoffnung auszudrücken, daß zumindest eine partielle Verwirklichung der in R\&A konzipierten Deutschlandpolitik noch möglich war, was voraussetzte, daß man es in der Abteilung trotz aller sonst immer wieder erkennbaren Resignation angesichts der „konservativen“ Tendenzen der Deutschen nicht für ausgeschlossen hielt, daß sich die Kräfte, die grundlegende Reformen befürworteten, doch noch durchsetzen könnten. Vor allem aber schien damit auch angedeutet, daß man die amerikanische Politik nicht als ideologisch fixiert sah: Auch wenn die US-Besatzungspolitik in den Augen der im State Department verbliebenen R\&A-Mitarbeiter kaum geeignet sein konnte, eine "wirkliche" Demokratisierung Deutschlands zu bewirken, schien man in der Abteilung doch noch immer davon auszugehen, daß ihr vorrangiges Ziel der Aufbau einer dauerhaften demokratischen Ordnung in Deutschland war.

Ganz offensichtlich unterstellte ORI auch nicht, daß sich hinter der amerikanischen Initiative zum wirtschaftlichen Zusammenschluß der Zonen die Absicht verbarg, einen westdeutschen Staat zu etablieren - zumindest sah der Entwurf keinen Weststaat vor, sondern skizzierte die allgemeinen Grundzüge einer gesamtdeutschen Regierung.

${ }^{38}$ Ein Jahr später legte die inzwischen als Office of Intelligence Research (OIR) geführte Abteilung einen Überblick über „German Proposals for the Organization of Nationalized Enterprises“ vor: NA, RG 59, OIR/(R\&A) 4437, 6.8. 1947; deutsch in Söllner (Hrsg.), Archäologie der Demokratie, Bd.2, S. 153-168. Die politische Brisanz dieses Themas kam darin allerdings kaum zum Ausdruck, was Söllner als (bewußte) Strategie interpretiert hat (a.a.O., S.117ff.); es ließe sich m. E. allerdings genausogut argumentieren, daß man die Brisanz dieser Frage in der Abteilung tatsächlich nicht länger gegeben sah, da man den Zeitpunkt für eine „social revolution" für verpaßt hielt; bezeichnend ist in diesem Zusammenhang, daß OIR zwischen „Sozialisierung" und "Verstaatlichung" (nationalization) unterschied.

${ }^{39}$ Winkler, Die amerikanische Sozialisierungspolitik, in: Winkler (Hrsg.), Politische Weichenstellungen, S. 88-110, verweist darauf, daß die im State Department entwickelten Konzeptionen für eine Demokratisierung Deutschlands die Verstaatlichung von Schlüsselindustrien durchaus vorsahen, und vertritt die These, ${ }_{n}$ daß das US-Außenministerium gegenüber den Forderungen von deutschen Sozialdemokraten und Gewerkschaftlern eine weitaus liberalere Haltung einnahm, als in der Literatur gemeinhin unterstellt wird“. 
Zwar waren die „desiderata der amerikanischen Politik dabei der leitende Gesichtspunkt, doch so wie ORI sie formulierte und interpretierte, waren damit keine Forderungen verbunden, die für die Sowjetunion grundsätzlich inakzeptabel sein mußten. Gerade in der überaus kontroversen Frage der föderalistischen oder zentralistischen Struktur eines künftigen deutschen Staates plädierte ORI für eine flexible Haltung der USA. Freilich erschien der von der Sowjetunion befürwortete Zentralismus in der Darstellung der Abteilung als schon geradezu idealer „Vorwand“ zur Schaffung einer starken demokratischen Zentralgewalt, die sich gegenüber einer Minderheit eventuell kommunistisch geführter Länder sehr viel besser würde behaupten können als eine von den Ländern in hohem Maße beeinflußbare Zentralregierung in einem stark föderalistischen System. Insofern könnte dieses Arbeitspapier als Dokument des Kalten Krieges gelesen werden: Obwohl ORI versuchte, Kompromißmöglichkeiten aufzuzeigen, wird die Eindämmung kommunistischen - und implizit sowjetischen - Einflusses in Deutschland als vitales amerikanisches Interesse stillschweigend vorausgesetzt.

Die Aussichten für die Bildung einer gesamtdeutschen Regierung beurteilte man in der Abteilung allerdings auch nicht sonderlich optimistisch. Die vielbeachtete Rede, die Außenminister Byrnes am 6.September 1946 in Stuttgart gehalten hatte, nahm ORI zum Anlaß, die "Controversial Issues in German Policy“ zu referieren und zu erläutern, ob und inwiefern Byrnes’ „Restatement of U.S. Policy“ Raum für eine gemeinsame alliierte Deutschlandpolitik ließ $\beta^{40}$.

Wie ORI ausführte, hatte Byrnes in seiner Rede in Stuttgart den Stellenwert einer zentralen deutschen Regierung für die US-Politik stärker betont, als dies in bisherigen Erklärungen geschehen sei ${ }^{41}$. Byrnes zufolge befürworteten die USA zwar eine Dezentralisierung, wünschten aber auch die Bildung einer demokratisch gewählten und konstituierten zentralen deutschen Regierung. Diese Position entspreche im wesentlichen der britischen, nicht aber der französischen und sowjetischen. Die französische Politik, die vor allem von Sicherheitsinteressen bestimmt werde, strebe eine entscheidende Schwächung Deutschlands an und befürworte deshalb eine möglichst lockere staatenbündische Organisation. Die Sowjetunion dagegen wolle einen zentralistisch strukturierten deutschen Staat und werfe den Westmächten vor, daß sich hinter ihrem Eintreten für eine föderalistische Organisation "nothing but a more or less veiled division of Germany into several autonomous states" verberge ${ }^{42}$. Auch Walter Ulbricht habe erklärt, daß die Schaffung der Bizone sowie die damit verbundenen amerikanischen Vorschläge nur die Teilung Deutschlands als politisches Ziel haben könnten. Nach Ansicht von ORI war vor diesem Hintergrund zu erwarten, daß sich die Sowjetunion der amerikanischen Politik gegenüber ablehnend verhalten würde und daß sich die Kluft zwischen den Westzonen und der Ostzone vertiefen würde.

Grundsätzlich verschiedene Positionen verträten die USA und die Sowjetunion auch hinsichtlich der Demokratisierung und Entnazifizierung. Byrnes habe erklärt, daß es

\footnotetext{
40 NA, RG 59, OCL/(R\&A) 4152, "Controversial Issues in German Policy Raised by Secretary Byrnes' Stuttgart Speech“, 24.9. 1946. Byrnes’ Rede ist abgedruckt in: Department of State, Germany 1947-1949, S.3-8.

41 Vgl. dazu auch NA, RG 59, OCL/(R\&A) 3782, „Centralism and Federalism in Germany“, 1.11. 1946.

42 A.a.O.
} 
die Fortschritte in diesen Bereichen inzwischen erlaubten, den Deutschen schrittweise die Verantwortung für ihre eigene Verwaltung und Regierung zu übertragen. Die Sowjetunion habe aber eine grundlegend andere Konzeption und sei der Ansicht, daß reaktionäre Kräfte noch viel zu stark, fortschrittliche und demokratische Kräfte dagegen noch $\mathrm{zu}$ wenig organisiert und schwach seien. In diesem Zusammenhang versuchte ORI - ähnlich wie auch schon in der Gewerkschaftsanalyse -, die sowjetischen Positionen gewissermaßen neutral als integralen Bestandteil der sowjetischen Demokratisierungskonzeption verständlich zu machen und aus dieser Perspektive die sowjetische Kritik an der Politik der westlichen Besatzungsmächte zu erklären. Die künftige Entwicklung der sowjetischen Politik schätzte man aber deshalb keineswegs unrealistisch ein. Angesichts der Ergebnisse der kürzlich in der sowjetischen Besatzungszone abgehaltenen Wahlen, die die ungebrochene Stärke antisozialistischer Gruppen des mittleren Bürgertums gezeigt hätten, mußte das sowjetische Ziel einer ,antifascist democracy“ nach Ansicht von ORI in absehbarer Zukunft nur mit Hilfe einer „revolutionary dictatorship“ erreichbar scheinen. Ein solches Vorgehen entspreche jedoch nicht dem erklärten Kurs sowjetischer Besatzungspolitik, und auf revolutionäre Entwicklungen in Deutschland hofften auch die Sowjets nicht. Sie würden vielmehr "democratic forms and processes" weiterhin ausbauen, gleichzeitig aber ohne Rücksicht auf Wahlergebnisse bestrebt sein, „[to] maintain and extend Soviet and pro-Soviet control over the economy and administration, and [to] integrate the Soviet Zone with the USSR's Eastern European orbit“. Große Bedeutung komme in diesem Zusammenhang wirtschaftlichen Kontrollen zu, und im Falle einer Wiederherstellung der wirtschaftlichen Einheit Deutschlands war nach Meinung von ORI damit zu rechnen, daß die Sowjetunion versuchen würde, „to penetrate to the west". Die enormen Kapazitäten der UdSSR als Absatzmarkt und Rohstofflieferant stellten dabei einen nicht zu unterschätzenden Faktor dar, und nach Ansicht von ORI konnte kein Zweifel daran bestehen, "[that their] ultimate objective is to bring the whole German economy into the Soviet orbit".

So seien im wirtschaftlichen Bereich auch die größten Unterschiede zwischen den Positionen der USA und der Sowjetunion zu verzeichnen. In den zentralen Problemen - der Behandlung Deutschlands als wirtschaftlicher Einheit und der Frage der Reparationen - sei die britische Position der amerikanischen ähnlich, und selbst die französische unterscheide sich eher „in formal matters“. So akzeptierten die Franzosen immerhin zumindest das Prinzip der wirtschaftlichen Einheit, während die Russen bislang nur entsprechende Lippenbekenntnisse abgelegt, sich aber tatsächlich der Behandlung Deutschlands als wirtschaftlicher Einheit widersetzt hätten. Hinsichtlich der Reparationsfrage verträten die USA und Großbritannien gemäß ihrer Interpretation der in Potsdam getroffenen Vereinbarungen die Ansicht, daß es keine Entnahmen aus laufender Produktion geben sollte, was von der Sowjetunion und Frankreich freilich nicht eingehalten würde.

Daß ORI aus dieser Übersicht der in Byrnes' Rede berührten „Controversial Issues“ kein Fazit zog, mag darauf schließen lassen, daß man dies für überflüssig hielt. In der Tat war die Erkenntnis, daß es Großbritannien und den USA nicht schwerfallen dürfte, einen ausreichenden "gemeinsamen Nenner" für eine einheitliche Politik zu finden, angesichts der Entwicklungen bereits obsolet; auch die Annahme, daß sich eine Einigung mit Frankreich problematischer gestalten, letztlich aber doch möglich sein würde, 
konnte nicht als Neuigkeit gelten - ebensowenig wie die Erkenntnis, daß die Gegensätze zwischen den Westmächten und der Sowjetunion zunehmend schärfer hervortraten.

Interessant ist jedoch, daß ORI die Unterschiede im wirtschaftlichen Bereich zwar als besonders augenfällig und in politischer Hinsicht gewichtig beschrieb, andererseits aber die grundsätzliche Verschiedenheit der Systeme anhand der unterschiedlichen Demokratisierungskonzeptionen illustrierte. Das war mitnichten ein zufälliges Arrangement, sondern reflektierte vielmehr eine von der Abteilung expressis verbis zwar nicht getroffene, aber in zahlreichen Studien erkennbare Unterscheidung zwischen Ursache und Anlaß für die Spaltung Deutschlands und die Anfänge des Kalten Krieges.

Erstmals war diese Unterscheidung in der Studie über die Entwicklung der Gewerkschaften angedeutet, wo ORI versucht hatte, die unterschiedliche Politik der Besatzungsmächte auf ihr unterschiedliches Verständnis von Demokratie und ihre unterschiedliche Interpretation der für die nationalsozialistische Machtübernahme entscheidenden Faktoren zurückzuführen. Diesen Erklärungsansatz versuchte die inzwischen als Office of Intelligence (OIR) geführte Abteilung Anfang März 1947 in einer Arbeit zur "Implementation of the Potsdam Declaration" auf alle wichtigen Bereiche alliierter Besatzungspolitik anzuwenden ${ }^{43}$. Konsequent wurde das Thema deshalb auf die Aspekte „Democratization and Denazification“ eingeschränkt, die beiden Elemente alliierter Besatzungspolitik also, die als nicht näher definierte Zielvorstellungen kaum kontrovers gewesen waren. In der umfassenden, hundert Seiten starken OIR-Studie wurden sie jedoch zum Ausgangspunkt einer unvermeidlich auseinanderstrebenden Entwicklung, die immer weniger reversibel zur Ausbildung zweier unterschiedlicher, ja gegensätzlicher Systeme im besetzten Deutschland und damit zu seiner Spaltung zu führen schien. Unvermeidlich schien diese Entwicklung insofern, als eine Demokratisierung Deutschlands nach dem westlichen Verständnis von Demokratie - bei allen aus der jeweiligen nationalen Tradition erwachsenden Nuancen - ganz andere Schritte erforderte, als nach kommunistischem Verständnis notwendig waren.

Wie OIR ausführte, verstünden die Russen unter Demokratisierung „first of all the introduction of certain fundamental changes in the social and economic structure". Nachdem solche Veränderungen - in der sowjetischen Zone konkret die Bodenreform und die Verstaatlichung von Schlüsselindustrien - durchgeführt seien, könne ein den neuen gesellschaftlichen Strukturen entsprechender politischer Apparat aufgebaut und Wahlen abgehalten werden. Nach Ansicht der Abteilung war auf diese Weise in der sowjetischen Zone zwar eine gewisse Grundlage für eine gesellschaftliche Demokratisierung geschaffen worden, doch sei dies "with scant regard for democratic forms and procedures" geschehen. OIR stellte dieses Vorgehen der Entwicklung in den westlichen Zonen gegenüber, „[where] these forms and procedures have in the main been observed". Die Westmächte verstünden unter Demokratisierung "first of all the replacement of the Nazi structure of government and political life with traditional liberaldemocratic procedures and institutions“. Nach westlichem Verständnis sei es "the essence of democracy $[\ldots]$ to allow the public will as thus formulated to use such procedures and institutions for whatever purposes and policies it chooses" - wobei man sich freilich beeilte hinzuzufügen: „at least in purely internal affairs“. Insofern entspreche es

43 NA, RG 59, OIR/(R\&A) 4286, „Implementation of the Potsdam Declaration: Democratization and Denazification" ${ }^{\circ}$, 5.3.1947. 
nicht den westlichen Vorstellungen, auf bestimmten gesellschaftlichen oder wirtschaftlichen Veränderungen zu insistieren. Als Ergebnis dieses Vorgehens hätten sich in den westlichen Zonen wieder die traditionellen gesellschaftlichen Gruppen und Strukturen herausgebildet, was nach Ansicht von OIR jegliche grundlegenden Reformen, die vielleicht doch noch erwogen werden könnten, erheblich erschweren würde.

In diesem Zusammenhang machte die Abteilung keinen Hehl daraus, daß man solche grundlegenden Reformen für unverzichtbar hielt, wenn die von den Westmächten eingeführten „democratic forms and procedures“ mehr als leere Formen und Verfahrensweisen sein sollten. OIR versuchte zu verdeutlichen, daß Entnazifizierung und Demokratisierung in den westlichen Zonen die autoritären und undemokratischen Strukturen in Bürokratie, Administration und Rechtswesen sowie im Bereich der Wirtschaft weitgehend unangetastet gelassen hatten, so daß eine Demokratie ohne Fundament aufgebaut worden sei, deren Stabilität - zumal vor dem Hintergrund der in R\&A-Studien immer wieder vertretenen Interpretation des Nationalsozialismus als Resultat struktureller, in der sozialen und wirtschaftlichen Verfassung Deutschlands liegender Probleme - überaus zweifelhaft erscheinen mußte.

Die Darstellung der in der sowjetischen Zone durchgeführten Reformen ließ dagegen deutlich erkennen, daß man in OIR der Ansicht war, daß sich die sowjetische Besatzungsmacht diese Versäumnisse nicht hatte zuschulden kommen lassen. Doch so positiv die einzelnen Demokratisierungsmaßnahmen als solche beschrieben wurden, so negativ fiel die Gesamtbeurteilung aus: Zwar waren die traditionellen Strukturen, auf die sich die Herrschaft autoritärer und antidemokratischer Eliten gestützt hatte, aufgebrochen worden, doch wollte man dies allein nicht als Demokratisierung gelten lassen. Je deutlicher sich abzeichnete, daß die sowjetische Besatzungsmacht keine demokratische Weiterentwicklung zuließ, sondern den einen Autoritarismus nur durch einen anderen ersetzte, desto schärfer formulierte OIR die Kritik an dieser Entwicklung, ohne sie freilich auf den ursprünglichen Ansatz auszudehnen.

Daß andererseits die Kritik der Abteilung an der westlichen Besatzungspolitik verhalten blieb, dürfte nicht zuletzt auf den institutionellen Rahmen zurückzuführen sein. Denn während die im State Department verfaßten Studien der Abteilung für die westlichen Besatzungszonen im wesentlichen eine Restauration des Status quo ante beschrieben und in ihr sowohl das verwirklichte negative Potential der Weimarer Republik wie auch ihre nicht realisierten Entfaltungsmöglichkeiten für eine demokratische Weiterentwicklung angelegt sahen, zeichneten die gewissermaßen privaten Versionen dieser Studien, die Mitarbeiter der Abteilung gelegentlich in politischen oder historischen Fachzeitschriften veröffentlichten, ein deutlich kritischeres und pessimistischeres Bild.

Wie weit sich die in diesen Veröffentlichungen entwickelten Überlegungen und Argumentationen einerseits mit denen in State Department-Studien deckten - manchmal bis zu identischen Formulierungen -, wieviel deutlicher aber andererseits die Beurteilungen ausfielen, läßt sich anhand eines im Juni 1947 publizierten Artikels Franz Neumanns illustrieren. Unter dem Titel Re-educating the Germans - The Dilemma of Reconstruction $^{44}$ präsentierte Neumann die zentralen Argumentationen und Interpreta-

44 Neumann, Re-educating the Germans - The Dilemma of Reconstruction, in: Commentary 3/6, Juni 1947, S.517-525; die folgenden Zitate 517f., Hervorhebungen im Text; wieder abgedruckt in Neumann, Wirtschaft, Staat, Demokratie, S.290-308. 
tionen, die die bis Anfang 1947 unter seiner Leitung stehenden ORI-Mitarbeiter in den knapp zwei Jahren seit Kriegsende entwickelt hatten und die ihre Beurteilungen auch in den folgenden Jahren entscheidend prägen sollten. Analog zu der OIR-Studie über die Umsetzung der in Potsdam getroffenen Vereinbarungen versuchte Neumann dabei erneut zu demonstrieren, daß sich die unterschiedliche Politik der Besatzungsmächte auf ihre unterschiedlichen Interpretationen des Begriffs Demokratie und des Phänomens Nationalsozialismus zurückführen ließe. So legte Neumann einmal mehr dar, daß die Westmächte den Nationalsozialismus als ein politisches Phänomen betrachteten, dem beizukommen sei, wenn man Nationalsozialisten aus Machtstellungen entfernte und den politischen Prozeß demokratisch gestaltete, worunter vor allem die Abhaltung freier Wahlen verstanden werde. Die Deutschen in den westlichen Besatzungszonen genossen so bereits beträchtliche politische Freiheit: „all the paraphernalia of democracy exist and the practices of political democracy are widely resorted to ". Was die künftige Entwicklung betraf, blieb Neuman jedoch überaus pessimistisch, denn angesichts der Erfahrungen der Weimarer Republik wollte er nicht ausschließen, „that political democracy may again give birth to Nazism, perhaps not while the occupation lasts, but once the vigilance of the occupying powers has been relaxed".

Dies zu verhindern, war nach Neumanns Darstellung das Anliegen der sowjetischen Besatzungspolitik. Entsprechend der sowjetischen Interpretation des Nationalsozialismus als politischen Ausdruck eines wirtschaftlichen und gesellschaftlichen Systems nämlich als "the ultimate form of monopoly capitalism" - erfordere die Vernichtung des Nationalsozialismus nach sowjetischem Verständnis die Zerstörung dieses Systems, und der Aufbau einer demokratischen Ordnung könne sich nicht in der Einführung freier Wahlen erschöpfen, sondern erfordere "a society without exploitation, in which the equality of citizens is not confined to the legal and political spheres but is extended into the economic". Daß sich die Sowjets einer Staatspartei bedienten, um diese Politik umzusetzen, beinhaltete nach Neumanns Ansicht jedoch wiederum die Gefahr, "that once that party achieves complete political control, freedom will not be established even when the socio-economic reforms are carried out ${ }^{*}$.

So war nach Neumanns Darstellung in Deutschland durch die unterschiedlichen politischen Konzeptionen und Praktiken der Besatzungsmächte ein Dilemma entstanden: "In the Western zones, there is the presence of freedom with the prospect of a rising neo-fascism; in the Soviet zone, there is the presence of repression with only a vague prospect of getting democracy. The choice between these alternatives is obviously no choice - there is neither a greater nor a lesser evil, there are two evils, and to be relieved of such a dilemma requires concrete action by the four powers."

Die düsteren Zukunftsaussichten, die Neumann hier für die deutsche Demokratie oder genauer: für die beiden „Experimente" mit der Demokratie in Deutschland zeichnete, heben sich deutlich von den zwar auch nicht optimistischen, aber doch zurückhaltenderen Beurteilungen der ORI-Studien des Jahres 1946 ab. Dennoch dürften die meisten Mitarbeiter der Abteilung Neumanns Einschätzung geteilt haben, denn ähnlich pessimistische Beurteilungen der Entwicklungen in Deutschland finden sich zunehmend deutlicher formuliert in den Analysen der folgenden zwei Jahre. Angesichts der sich zuspitzenden Konfrontation zwischen den beiden Großmächten konnte man in der Abteilung freilich kaum eine andere Position einnehmen, da man mit Neumann der Auffassung war, daß das „Dilemma“ in Deutschland nur aufgelöst werden könnte, wenn die 
Kriegsallianz zur praktischen Kooperation zurückfände ${ }^{45}$. Vor dem Hintergrund der schon in R\&A entwickelten Vorstellungen, die für die vom State Department übernommenen Mitarbeiter der Abteilung offensichtlich ihre Gültigkeit behielten, war die Teilung Deutschlands - ob sie in Realisierung alliierter Teilungspläne vollzogen wurde oder sich als Reflex des stufenweise manifest werdenden Systemgegensatzes zwischen demokratischem Kapitalismus und autoritärem Kommunismus ausbildete - unvereinbar mit dem Entstehen einer stabilen Demokratie in Deutschland. Das galt um so mehr, als man mit Neumann in beiden der in Deutschland durchgeführten Experimente mit der Demokratie wenig von dem verwirklicht sah, was man selbst als unverzichtbar für eine dauerhafte Demokratisierung Deutschlands erachtete. Auch in dieser Hinsicht bildeten die in R\&A entwickelten Konzeptionen den Maßstab: Danach war in der sowjetischen Besatzungszone die Grundlage für eine gesellschaftliche Demokratisierung geschaffen worden, und in den Westzonen waren die traditionellen Verfahrensweisen und Institutionen liberaler Demokratie eingeführt worden, doch fehlte im Westen das Fundament und im Osten der „Überbau“. Angesichts des von ORI vermittelten Bildes vom politischen Verhalten der Deutschen in den ersten beiden Nachkriegsjahren konnte wenig Hoffnung bestehen, daß sie - wieder in die Selbständigkeit entlassen - diese „Fehlkonstruktionen" letztlich doch noch zu einer stabilen Demokratie ausbauen würden.

\section{Die „deutsche Frage“ im Kalten Krieg}

Wenn die Leser des Commentary im Juni 1947 Franz Neumanns Artikel zur Umerziehung der Deutschen und dem "Dilemma of Reconstruction “ entnehmen konnten ${ }^{46}$, daß die USA und die Sowjetunion für das „Dilemma“ in Deutschland - nämlich die Begründung zweier gegensätzlicher Systeme, aber keiner deutschen Demokratie - gleichermaßen Verantwortung trugen und es nur gemeinsam würden lösen können, so konnten die Leser der Juli-Ausgabe von Foreign Affairs dem Artikel eines mysteriösen Mr. X über die Sources of Soviet Conduct entnehmen ${ }^{47}$, "that there can never be on Moscow's side any sincere assumption of a community of aims between the Soviet Union and powers which are regarded as capitalist". Die USA müßten die Sowjetunion deshalb in der politischen Arena als Rivalen, nicht etwa als Partner betrachten und durch eine "policy of firm containment" versuchen, „to confront the Russians with unalterable counterforce at every point where they show signs of encroaching upon the interests of a peaceful and stable world". Welcher der beiden Artikel den Zeitgeist einfing, war keine Frage: In den Ausführungen des Mr. X fand ein politisch interessiertes Publikum die Leitgedanken einer neuen, mit der im März verkündeten „Truman-Doktrin“ eingeleiteten amerikanischen Politik gegenüber der Sowjetunion formuliert ${ }^{48}$.

45 Ähnlich zur selben Zeit übrigens auch R\&A-Mitarbeiter Carl E. Schorske in einer Veröffentlichung des Council on Foreign Relations: The Development of a Democratic Germany, in: Price/Schorske, The Problem of Germany, S.138ff.

${ }^{46}$ Siehe oben VIII., 1. Teil.

47 [George Kennan], The Sources of Soviet Conduct, in: Foreign Affairs 25 (1947), S. 567-582.

${ }^{48}$ Vgl. dazu Gaddis, Harry S. Truman and the Origins of Containment, in: Merli/Wilson (Hrsg.), Makers of American Diplomacy, S.189-218; sowie Donovan, Conflict and Crisis, S.279ff.; Yergin, Shattered Peace, S. 245 ff.; Loth, Die Teilung der Welt, S. $120 \mathrm{ff}$. 
Daß sich Mr. X bald als der Leiter des im State Department neu eingerichteten Policy Planning Staff, George Kennan, entpuppte, mußte den Eindruck, daß seine Ausführungen offizielles Denken widerspiegelten, noch verstärken.

Freilich war mitnichten eindeutig, was Kennan unter dem Begriff „Containment" genau verstanden wissen wollte und wie er sich eine amerikanische Eindämmungspolitik gegenüber der Sowjetunion vorstellte ${ }^{49}$. Der angesehene Kolumnist Walter Lippmann interpretierte Kennans Ausführungen als Plädoyer für eine globale Konfrontationspolitik und kritisierte, daß Kennan unterstelle, daß die Sowjetunion grundsätzlich kompromißunfähig und kooperationsunwillig sei ${ }^{50}$. Obwohl sich Kennan von Lippmann offenbar mißverstanden fühlte, unterließ er eine Richtigstellung ${ }^{51}$.

Ebensowenig eindeutig wie seine Ausführungen in Foreign Affairs war allerdings auch die „Urfassung“ dieses Artikels, Kennans als „langes Telegramm“ in die Geschichte eingegangene Analyse der sowjetischen Politik, die er im Februar 1946 noch als Mitarbeiter der amerikanischen Botschaft in Moskau nach Washington gekabelt hatte ${ }^{52}$. Ähnlich wie in Foreign Affairs hatte Kennan die sowjetische Weltsicht als neurotisch und irrational, die Politik als ideologiebestimmt und auf Expansion gerichtet beschrieben; er verneinte ein sowjetisches Interesse an einem Modus vivendi mit den USA und beschwor so insgesamt ein Menetekel, dem er schließlich selbst „einige ermutigendere Bemerkungen “ anfügen wollte ${ }^{53}$. Diese liefen im wesentlichen darauf hinaus, daß kein Grund zu „antisowjetischer Hysterie“ bestehe, weil die Sowjetunion keine unmittelbare militärische Bedrohung darstelle und weil die westliche Welt, wenn sie nur genügend Zusammenhalt, Entschlossenheit und Kraft aufbrächte, eine Expansion der sowjetischen Macht verhindern könnte, um dann abzuwarten, bis das Sowjetsystem sozusagen an seinen inneren Konflikten zugrunde gehen würde - womit Kennan der von ihm beschriebenen marxistischen Erwartung eine vergleichbare kapitalistische entgegensetzte.

Kennans Zweideutigkeit - die Beschwörung eines Menetekels, gefolgt von „einigen ermunternden Bemerkungen“ - schien freilich Methode zu haben. Ähnlich wie dieses Telegramm baute Kennan nämlich offenbar auch einen Vortrag zum Soviet Way of Thought and Its Effect on Foreign Policy auf, den er Anfang Januar 1947 vor Mitgliedern des Council on Foreign Relations hielt ${ }^{54}$ : Nachdem er die sowjetische Weltsicht wiederum als irrational und ideologiebestimmt charakterisiert hatte, versicherte er seinen alarmierten Zuhörern, daß kein Grund zur Verzweiflung bestehe, da es für die USA und den Westen möglich sei, ,to contain Russian power, if it [. . is] done courteously and in a non-provocative way, long enough so that there might come about in-

49 Dies konzediert Kennan selbst in seinen Memoiren: ders., Memoiren eines Diplomaten, S. $357 \mathrm{ff}$. Vgl. außerdem Paterson, The Search for Meaning, in: Merli/Wilson (Hrsg.), Makers of American Diplomacy, S. 249-284; Gaddis, Containment: A Reassessment, in: Foreign Affairs 55 (July 1977), S. 873-887; und ders., Strategies of Containment.

50 Die zwölf Kolumnen, in denen sich Lippmann im September und Oktober 1947 mit Kennans Artikel auseinandersetzte, erschienen noch im selben Jahr als Broschüre: Lippmann, The Cold War; neu aufgelegt 1972 (unter Einschluß von Kennans Artikel).

51 Kennan, Memoiren eines Diplomaten, S. $357 \mathrm{ff}$.

52 Abgedruckt in FRUS, 1946, VI, S. 696-709, sowie im Anhang zu Kennans Memoiren.

53 In seinen Memoiren deutet Kennan an, daß er selbst manche seiner Warnungen im Rückblick für reichlich übertrieben hielt, siehe z.B.S.297, 304.

54 Vgl. dazu und zum Folgenden Wala, Winning the Peace, S. $107 \mathrm{f}$. 
ternal changes in Russia“. Kennan soll in diesem Zusammenhang eine "get-tough-policy“ abglehnt haben und statt dessen für eine „würdevolle und selbstsichere Haltung“ der USA in der Weltpolitik eingetreten sein.

Daß Kennans Fähigkeiten im State Department geschätzt wurden, ist angesichts dessen, daß er mit der Leitung des im Frühjahr 1947 eingerichteten Policy Planning Staff betraut wurde, kaum zu bezweifeln. Fraglich erscheint jedoch, ob daraus ohne weiteres auf den „Einzug des antikommunistischen Kampfgeistes ins State Department" geschlossen werden kann ${ }^{55}$. Abgesehen davon, daß Kennan selbst in seinem "Antikommunismus" zweideutig blieb, belegt auch so manches Dokument, auf das sich diese und ähnliche Einschätzungen stützen dürften, vielleicht nur scheinbar eindeutig einen „antikommunistischen Kampfgeist“. Interessant und aufschlußreich erscheint in diesem Zusammenhang, wie OIR die Entwicklungen auf dem „Kalten-Kriegsschauplatz“ Deutschland analysierte und interpretierte.

Anfang März 1947, einen Tag bevor die im State Department verbliebenen, inzwischen als Office of Intelligence Research (OIR) firmierenden R\&A-Mitarbeiter mit ihrer Studie zur „Implementation of the Potsdam Declaration“ eine Analyse der alliierten Besatzungspolitik vorgelegt hatten, die ähnlich wie Neumanns Artikel im Commentary kaum Argumente für eine - wie auch immer verstandene - „Containment"-Politik hergab, erschien ein ebenfalls in OIR ausgearbeiteter Bericht über „Reparations Removals from the Soviet Zone of Germany ${ }^{\text {“56, }}$, in dem einleitend die Rolle der Reparationen in der sowjetischen Politik in einer Weise dargestellt wurde, die einer „Kalten-Kriegserklärung“ gleichzukommen schien. Ausgehend von der Behauptung, daß zahlreiche Beobachter festgestellt hätten, daß ein grundsätzlicher Unterschied zwischen der anglo-amerikanischen und der sowjetischen Sicht und Behandlung der Nachkriegsprobleme in Deutschland bestehe, wurde ausgeführt, daß die Politik der Westmächte durch ihre „continuing and almost exclusive preoccupation with the German problem itself" charakterisiert sei. Wie erklärt wurde, sei der ausschließliche Zweck der Besatzung ursprünglich „as one of political neutralization and military, industrial, and ideological disarmament of Germany" definiert worden. Vorrangig unter diesem Gesichtspunkt hätten die Westmächte zunächst auch den Abbau von Produktionsanlagen gesehen, doch gerade wegen ihres starken Interesses an den deutschen Problemen selbst erkannten sie „increasingly and acutely [...] the double-edged character of a program which, while temporarily depriving Germany of the means with which to wage war, risks jeopardizing the objective of neutralizing Germany by impoverishing the German people to a point where participation, , as a pawn or partner', in another war may appear to them as the only salvation" 57 .

55 Söllner (Hrsg.), Archäologie der Demokratie, Bd.2, S.61, unter Verweis auf Steininger, Deutsche Geschichte, Bd. I, S.221, wo behauptet wird, daß Kennans Analyse vor allem „im State Department auf größtes Interesse stieß, denn dort gab es genügend Beamte, die - genau wie Kennan - die sowjetische Außenpolitik als militant, aggressiv und expansionistisch ansahen “.

${ }^{56}$ NA, RG 59, OIR/(R\&A) 3525.16, 4.3. 1947, sowie NA, RG 59, OIR/(R\&A) 3525.16, Appendix A: „List of Plants Reported Partially or Totally Dismantled“, 4.3. 1947; im Tenor ähnlich die entsprechenden Abschnitte in NA, RG 59, OIR/(R\&A) 4776, "The Effects of the Soviet Occupation on German Unity", 2.11. 1948; siehe außerdem NA, RG 59, OIR/(R\&A) 4792, „Soviet Takings From Germany, 1945-48“, 15.11. 1948.

57 Die Formulierung „pawn or partner“ ist der Byrnes-Rede in Stuttgart entnommen, vgl. Department of State, Germany 1947-1949, S.3. 
Die sowjetische Politik schiene vor allem durch zwei Gesichtspunkte bestimmt ${ }^{58}$. Wie den Westmächten sei auch der Sowjetunion das künftige Verhältnis zwischen Deutschland und den Großmächten wichtig; dementsprechend sei die Sowjetunion gegen eine ausschließliche Kontrolle Deutschlands durch die Westmächte und versuche, ihren eigenen Einfluß und ihre Kontrolle über Deutschland zu erhalten bzw. zu erweitern. Anders als die Westmächte betrachteten die Sowjets die Besatzung aber auch unter dem Gesichtspunkt ihres Beitrages zur industriellen Kapazität und zum Lebensstandard der Sowjetunion. Wie OIR erklärte: „This policy serves their short-run interest in repairing the destruction caused by the war, which exceeds that suffered by any other Allied nation. It also serves their long-run objective: to develop the Soviet Union's industrial potential - and thereby its military potential - until it ,equals and surpasses" the economic and military potential of any other great power."

Diese beiden Ziele sowjetischer Politik - nämlich die Sicherung sowjetischen Einflusses in Deutschland und die Erlangung eines Maximums an Reparationen - ließen sich bis zu einem gewissen Grade miteinander vereinbaren; als Beispiel führte OIR an, daß es den Russen gelungen sei, „to effect drastic political, economic, and social changes in their zone while at the same time bleeding the zone economically". Häufiger seien diese beiden Ziele jedoch nicht miteinander vereinbar, und in diesen Fällen hätten die Russen bislang meist ihre langfristigen politischen Ziele kurzfristigen wirtschaftlichen Vorteilen untergeordnet. Solange etwa die Demontage von Industrieanlagen ihren unmittelbaren Interessen dienlich schien, sei diese ohne Rücksicht auf andere Ziele - wie etwa Vollbeschäftigung oder Verstaatlichung - durchgeführt worden. Sobald Reparationen aus laufender Produktion vorteilhafter erschienen, hätten die Sowjets diesen Kurs eingeschlagen, obwohl damit eine Anhebung industrieller Produktion auch in jenen Gebieten Deutschlands verbunden sei, "which the Russians probably consider definitely as outside the Soviet sphere of influence in Europe“. Daraus glaubte OIR entnehmen zu können, "[that the] effect of the reparations program on Germany - on its ability and desire to wage war - [...] seems to have taken second place. [. . .] in most instances so far, the immediate needs of the Soviet Union have seemed the major concern of Soviet policy in Germany; the effects of Soviet policy on the political and economic complexion of Germany itself have appeared to be of lesser importance".

Insgesamt schien es von dieser Darstellung der sowjetischen Deutschlandpolitik nicht weit zu der Feststellung, "[that the] ultimate, over-all objective of the USSR [...] the extension of Soviet hegemony over the whole of Germany" sei - doch war das mitnichten die Schlußfolgerung von OIR. Mit diesem Satz charakterisierte vielmehr die "Konkurrenz" von der Central Intelligence Group in einem vier Wochen nach der OIR-Studie vorgelegten Papier ${ }^{59}$ die sowjetische Politik, was ihr, wie aus der beigehefteten Kritik hervorgeht, von OIR den Vorwurf einbrachte, unzulässig zu vereinfachen: „It minimizes or neglects the alternative policies which the USSR may pur-

${ }^{58}$ Vgl. dazu und zum Folgenden auch Geyer, Von der Kriegskoalition zum Kalten Krieg, in: ders. (Hrsg.), Osteuropa-Handbuch. Sowjetunion. Außenpolitik, S. 343-381.

59 ORE 11/1, Central Intelligence Group, „Review of the Soviet, British, and French Programs with Respect to Germany“, 8.4. 1947, aus den Beständen der Truman Library, Papers of Harry S. Truman, President's Secretary File, in: CIA Research Reports, Europe 1946-1970, [Microfilm Publication], II, 0226 (künftig zitiert als: Truman/PSF - CIA/MF). 
sue in Germany.“ Nach Meinung von OIR war für eine Beurteilung der sowjetischen Politik zu berücksichtigen, daß die Sowjetunion eventuell eine Teilung und dauerhafte Schwächung Deutschlands bevorzugen oder politische Interessen zugunsten konkreter wirtschaftlicher Vorteile zurückstellen könnte.

Diese Kritik der Abteilung an einer Charakterisierung der sowjetischen Politik, die auf den ersten Blick auch als Fazit der OIR-Studie hätte durchgehen können, verweist auf den Unterschied der von OIR vertretenen Interpretation der „sources of Soviet conduct" und der von Kennan vertretenen. Kennans Thesen von der Irrationalität und der Ideologiegebundenheit der sowjetischen Politik ließen die Sowjetunion als unberechenbare und übelwollende Macht erscheinen, deren Expansionsgelüste die Welt in einen Kampf zwischen Gut und Böse stürzten. In der Darstellung von OIR erschien die Sowjetunion dagegen als eine Großmacht, die - wie es Großmächte seit eh und je getan hatten - ihre Interessen durchzusetzen suchte und dabei in der Wahl ihrer Mittel nicht zimperlich war. Sobald sie dabei die Interessen der USA gefährdete, mußten die USA - wie es Großmächte seit eh und je getan hatten - dies zu verhindern suchen. Die Konflikte zwischen beiden Großmächten waren in dieser Sichtweise traditionelle Interessenkonflikte, die mit traditionellen Mitteln gelöst werden konnten ${ }^{60}$ und insofern auch die Möglichkeit eines Interessenausgleichs nicht grundsätzlich ausschlossen.

Während OIR damit die Teilnahme am Kalten Krieg zu verweigern schien, war es nach Darstellung der Abteilung doch eindeutig die Sowjetunion, die mit ihrer Reparationspraxis einer gemeinsamen, an den in Potsdam formulierten Zielvorstellungen orientierten alliierten Deutschlandpolitik Hindernisse in den Weg stellte. Bemerkenswert ist in diesem Zusammenhang, daß OIR behauptete, die Westmächte hätten stets eine Neutralisierung Deutschlands angestrebt. Während sich argumentieren ließe, daß die Vorstellung eines neutralen Deutschlands letztlich allen Überlegungen zugrunde lag, die die „deutsche Frage“ nicht durch die Abgrenzung von Einflußsphären lösen wollten, sondern dezidiert auf die weitere Kooperation der Siegermächte setzten ${ }^{61}$, war die Neutralisierung Deutschlands nie offiziell als Ziel amerikanischer Politik definiert worden - nicht zuletzt die „policy of postponement“ hatte der Formulierung umfassender Konzeptionen, wie sie dafür notwendig gewesen wären, entgegengestanden. Entsprechende Überlegungen waren allerdings möglicherweise in manchen der Planungsstäbe angestellt worden; so waren ja auch in R\&A im ersten Halbjahr 1944 eine ganze Reihe von Denkschriften entstanden, die eine „Neutralisierung“ Deutschlands insofern vorsahen, als sie ein demilitarisiertes und demokratisches Deutschland, das weder einer britischen noch sowjetischen Einflußsphäre angehören sollte, in „some

${ }^{60}$ Freilich deuten auch viele Äußerungen Kennans darauf hin, daß er mit "Containment" letztlich nichts anderes als eine globale, bipolare Version der klassischen „balance of power"-Politik verband, vgl. dazu z.B. den bei Frohn, Neutralisierung, S.127 zitierten Auzug eines Briefes von Kennan an Bohlen vom 26.1. 1945.

${ }^{61}$ Vgl. dazu die Interpretation der "Original Premises of United States Policy in Germany“ in einer Denkschrift Kindlebergers: "Underlying all this policy [...] was the view that Germany's most appropriate penance for her sins of aggression would be to serve as neutral ground between East and West where negotiation and compromise would provide a basis for adjustment“, in: Kindleberger, Marshall Plan Days, S.13. Siehe außerdem die Ausführungen zum Stellenwert von Neutralisierungsvorstellungen in der amerikanischen Deutschlandpolitik 1945/46 in Frohn, Neutralisierung, S. $39 \mathrm{ff}$. 
form of European union not directed against either Britain or Russia, but integrated with both" eingebunden sehen wollten ${ }^{62}$. Die in diesem Zusammenhang formulierten Vorstellungen waren in dem von leitenden Mitarbeitern der R\&A-Branch verfaßten Memorandum über die "American Security Interests in the European Settlement“ zusammengefaßt, das tatsächlich als eine Art Grundsatzpapier für die von der Abteilung entwickelten Positionen gelten kann.

Der Umstand, daß mit Edward Mason einer der Autoren dieser R\&A-Denkschriften Mitglied des Ende Juli 1946 im State Department eingesetzten Policy Committee on Germany war und daß der Leiter dieser Gruppe, James Riddleberger, die Arbeit von R\&A offenbar stets geschätzt hatte ${ }^{63}$, könnte möglicherweise ein Grund dafür sein, $\mathrm{da}$ auch dieses Gremium in seiner Mitte September 1946 vorgelegten Denkschrift zur langfristigen amerikanischen Deutschlandpolitik feststellte: "It is still true, as it was a year ago, that the United States hopes eventually to see established a Germany that is neutral toward surrounding powers. "64 Auch die weitere Zusammenfassung der bisherigen Leitgedanken der amerikanischen Deutschlandpolitik deckte sich mit den von R\&A vertretenen Positionen: Den Ausführungen des Komitees zufolge war mit der von den USA angestrebten Neutralität Deutschlands die Vorstellung eines Deutschlands verbunden „incapable of making war, economically recovered and capable of contributing to the recovery of Europe, and finally a Germany that enjoys the substance as well as the forms of democratic government " ${ }^{\text {65 }}$. Wenn an anderer Stelle nochmals betont wurde, daß es stets die grundlegende Zielvorstellung der amerikanischen Politik gewesen sei, „that Germany shall be politically independent of other powers and militarily available to none", und daß auch die deutschen Wirtschaftsbeziehungen mit anderen Ländern "without discrimination or favor" gestaltet werden müßten, war damit wohl mehr als eine fast schon tautologische Definition der amerikanischen Neutralisierungskonzeption verbunden.

Daß es gerade diese unverzichtbaren Elemente einer Neutralisierung Deutschlands waren, die im Frühjahr 1947 - auch nach Darstellung von OIR - durch die sowjetische Politik ernstlich gefährdet schienen, mußte Konsequenzen für die amerikanische Politik haben. Man konnte dabei entweder im Sinne der von der CIG vertretenen Posi-

${ }^{62}$ Vgl. dazu und zum Folgenden V., 2. Teil.

${ }^{63}$ Zum Komitee oben VIII., 1. Teil; zu Riddlebergers Wertschätzung für die Arbeit von R\&A: NA, RG 226, E 1, b 3, f: Europe-Africa Division 1945: Neumann an Langer u. a., 22.5. 1945.

${ }^{64}$ Zit. nach Frohn, Neutralisierung, S. 38 [ohne die Hervorhebungen vom Verfasser].

${ }^{65}$ Frohn, in dessen Argumentation die im State Department ausgearbeiteten Neutralisierungskonzeptionen eine zentrale Rolle spielen, geht auf eventuell relevante, während der letzten beiden Kriegsjahre entwickelte Vorstellungen nicht ein; seiner Darstellung zufolge war es erst die intensive Diskussion im Frühsommer 1946, die im State Department „bis Ende Juni 1946 zu einem weitgehenden deutschlandpolitischen Konsens" zugunsten eines neutralen, in eine europäische Ordnung eingebundenen Deutschlands führte, worauf im September 1946 „die einzelnen schrittweise entwickelten Elemente der amerikanischen Deutschlandpolitik erstmals als Neutralisierungskonzept formuliert und zugleich als Alternative zur drohenden Teilung Deutschlands neu akzentuiert" wurden; Frohn, Neutralisierung, S.72 und 138. Nicht gestellt wird dabei die Frage, wie es zu erklären ist, daß sich trotz der zuvor ( $\mathrm{S} .17 \mathrm{ff}$.) beschriebenen Unklarheit über die langfristigen Ziele der amerikanischen Deutschlandpolitik „die einzelnen schrittweise entwickelten Elemente der amerikanischen Deutschlandpolitik“ problemlos als "Neutralisierungskonzept" formulieren ließen. 
tion davon ausgehen, daß die UdSSR als „ultimate, over-all objective [...] the extension of Soviet hegemony over the whole of Germany " anstrebe, oder man konnte mit OIR annehmen, daß die Sowjetunion auch "alternative policies" mit dem Ziel einer Teilung und dauerhaften Schwächung Deutschlands verfolgen oder unter Umständen politische Interessen zugunsten konkreter wirtschaftlicher Vorteile zurückstellen könnte. Der wesentliche Unterschied bestand darin, daß das amerikanische Interesse an einem neutralen Deutschland im ersten Fall obsolet erscheinen mußte, während seine Verwirklichung im zweiten Fall zwar prekär, aber noch nicht ausgeschlossen schien. $\mathrm{Da}$ beide Positionen letztlich spekulativ waren, konnte dieser Unterschied für die Formulierung einer realistischen und verantwortungsvollen Politik in der Praxis allerdings nur geringfügige Bedeutung haben - sie mochte zwar auf das Beste hoffen, mußte aber versuchen, das Schlimmste zu verhindern ${ }^{66}$.

Eine solche Haltung schien dann tatsächlich aus der Anregung zur Entwicklung eines europäischen Wiederaufbauprogramms zu sprechen, die Außenminister Marshall Anfang Juni 1947 während einer Rede in Harvard vortrug ${ }^{67}$. Wenn Marshall die Unterstützung der USA bei der Ausarbeitung und Umsetzung dieses Programms zusagte, mochte dies vor dem Hintergrund der Truman-Doktrin als ein auf Westeuropa beschränktes Angebot interpretiert werden, durch das die USA ein Gegengewicht zum Ausbau der sowjetischen Einflußsphäre in Osteuropa schaffen wollten. Doch Marshall schloß in seinen Ausführungen bekanntlich weder die osteuropäischen Staaten noch die Sowjetunion aus; dementsprechend wurde der sowjetische Außenminister auch von Großbritannien und Frankreich, die die Initiative bei den Vorbereitungen für die Ausarbeitung des von Marshall angeregten Programms übernahmen, zu Beratungen eingeladen. Andererseits war kaum anzunehmen, daß die amerikanische Prämisse einer Einbeziehung der deutschen Wirtschaft in dieses Wiederaufbauprogramm - mit allen ihren Konsequenzen, vor allem dem Wiederaufbau der deutschen Wirtschaft selbst, deren gesteigerte Produktion nicht etwa für Reparationen verwendet werden sollte - für die Sowjetunion akzeptabel war. Dennoch konnte das amerikanische Angebot von Wirtschaftshilfe zumindest als Test dafür angesehen werden, ob die Sowjetunion, wie OIR gemeint hatte, tatsächlich bereit war, politische Interessen zugunsten konkreter wirtschaftlicher Vorteile zurückzustellen. Dieser Test fiel bekanntlich negativ aus - oder, wenn man unterstellt, daß eine sowjetische Beteiligung nicht wirklich erwünscht war, positiv ${ }^{68}$. Mit der sowjetischen Ablehnung des Marshall-Plans war freilich auch eine entscheidende Weichenstellung für die Spaltung Europas vollzogen.

${ }^{66}$ In diesem Zusammenhang sind allerdings auch innenpolitische Faktoren wie die seit November 1946 zuungunsten der Demokraten veränderten Mehrheitsverhältnisse in Senat und Repräsentantenhaus zu berücksichtigen, vgl. z. B. die Hinweise bei Frohn, Neutralisierung, S. 86, sowie Krieger, General Lucius D. Clay, S.203 f. zum Wechsel von Byrnes zu Marshall.

${ }^{67} \mathrm{Zu}$ Vorgeschichte und Entstehung des sog. Marshall-Plans Gimbel, The Origins of the Marshall Plan; Frohn, Neutralisierung, S. 86ff., sowie die entsprechenden Beiträge in Kindleberger, Marshall Plan Days. Marshalls Rede ist z.B. abgedruckt in Schlesinger (Hrsg.), The Dynamics of World Power, I, S. 52-54.

${ }^{68}$ Die Bewertung der Intentionen und Auswirkungen des Marshall-Plans ist strittig, vgl. dazu z. B. Daniel, Dollardiplomatie in Europa; Mee, The Marshall Plan; Milward, The Reconstruction of Western Europe; Abelshauser, Hilfe zur Selbsthilfe, in: VfZ 37 (1989), S. 85-113. 
Ausgerechnet vor diesem Hintergrund, der keiner der Hoffnungen, aber allen Kassandrarufen der R\&A-Branch entsprach, wuchs dem von R\&A so oft vertretenen Argument, daß ein wirtschaftlich drastisch geschwächtes Deutschland den nach dem Krieg notwendigen europäischen Wiederaufbau beeinträchtigen würde ${ }^{69}$, bald der Rang einer Binsenwahrheit zu. Auch die Zusammenhänge zwischen wirtschaftlicher und politischer Stabilität in Deutschland und Europa, auf die in R\&A-Studien so oft verwiesen worden war, wurden nun - freilich für ein geteiltes Deutschland und ein geteiltes Europa - allgemein anerkannt ${ }^{70}$.

Für die Deutschlandpolitik der Westmächte hatte die Einbeziehung der westlichen Besatzungszonen in die amerikanische Wirtschaftshilfe weitreichende Folgen, da sie den Ausbau der Bizone zur Vorform eines westdeutschen Staates mit sich brachte ${ }^{71}$. $\mathrm{Da}$ sich die Westdeutschen der Risiken und Kosten der damit verbundenen Verbesserung ihrer wirtschaftlichen Situation und ihres politischen Status bewußt waren, zeichnete OIR in einem Bericht über die "Reaction to the E.R.P. [European Recovery Program] in Western Germany" auf'. In OIR selbst hatte man allerdings offenbar trotz der Weichenstellung, die mit Einrichtung und Ausbau der Bizone, der Vorbereitung der Währungsreform und der Einbeziehung der westlichen Zonen in den Marshall-Plan für die Gründung eines westdeutschen Staates vollzogen schien, die Hoffnung auf eine Vermeidung einer endgültigen Spaltung Deutschlands noch nicht aufgegeben. Im Herbst 1947 entstand - möglicherweise in Vorbereitung der auf Ende

${ }^{69}$ Vgl. dazu oben V., 2. Teil; siehe auch das bei Kindleberger, Marshall Plan Days, S. $3 \mathrm{ff}$. abgedruckte Memorandum.

${ }^{70}$ Peterson, American Occupation, S. 37, hat im Zusammenhang mit seiner Darstellung der Intervention Morgenthaus festgestellt: „The policy of 1947 was [...] ready by August 1944, but folly intervened "; andererseits verweist er aber selbst auf das grundsätzlich veränderte politische Klima, in dem die „Politik von 1944“ 1947 umgesetzt wurde: "The Cold War meant that the conservative fear of Communism gradually replaced the liberal fear of fascism [...] the intent until 1947 was largely liberal, that is, to change things, but the intent thereafter largely conservative." (S.351)

${ }^{71}$ Die wichtigsten Stationen dieser Entwicklung beschreibt Benz, Die Gründung der Bundesrepublik. Außer den im folgenden noch genannten bzw. in VIII., 3. Teil, ausführlicher erörterten OIR-Studien begleitete die Abteilung diese Entwicklung - meist ohne die Dimension der Westintegration zu problematisieren - vor allem mit Arbeiten zu wirtschaftlichen Fragen: NA, RG 59, OIR/(R\&A) 4427, „Economic Situation and Prospects in the American and Britisch Zones of Germany", 3.6. 1947; NA, RG 59, OIR/(R\&A) 4390, "The Effects of a Financial Reform on German Production and Domestic and Foreign Trade“, 11.7. 1947; sowie NA, RG 59, OIR/(R\&A) 4392, "Currency Reform and Grain Collections in Germany", 2.6. 1947. Trokken referierende Berichte, in denen eine politische Analyse weitgehend fehlt und auf die nicht näher eingegangen wird, sind außerdem: NA, RG 59, OIR/(R\&A) 4437, „German Proposals for the Organization of Nationalized Enterprises", 6.8. 1947; NA, RG 59, OIR/(R\&A) 4724, „German Proposals for a Federal Constitution“, 6.8. 1948; NA, RG 59, OIR/(R\&A) 4724.1, „New Soviet Zone Directive for a National Constitution for Germany“, 15.9. 1948. Außerdem stellte OIR biographische Informationen bereit: NA, RG 59, OIR/(R\&A) 3197.6, „Principal German Officials (Bi-Zonal Economic Council)“, 18.7. 1947; NA, RG 59, OIR/(R\&A) 3197.7, „Principal German Officials“, 16.4. 1948.

72 NA, RG 59, OIR/(R\&A) 4677, 15.5. 1948. Insgesamt glaubte OIR jedoch feststellen zu können: „Although still hesitant about the consequences of ERP for German unity and economic reform and sceptical of the worth of its promises, the Western Germans, being confronted by great want, are turning toward support of the aid program and are anxious for its success." 
November angesetzten fünften Außenministerkonferenz in London - eine Serie von Studien ${ }^{73}$, die als Aktualisierung der Arbeiten vom August 1946 gelesen werden können $^{74}$. Wie schon im Jahr zuvor versuchte die Abteilung, die amerikanischen Interessen im Hinblick auf die wichtigsten Aspekte der "deutschen Frage“ in einer Weise zu bestimmen, die Raum für Kompromisse mit der Sowjetunion ließ. So versicherte OIR beispielsweise, daß die SED bei einer Zulassung auf gesamtdeutscher Ebene keine nennenswerten Stimmengewinne erzielen würde, während andererseits zu erwarten stünde, daß die SPD, auch wenn sie, wie anzunehmen sei, nur unter bestimmten Einschränkungen in der sowjetischen Besatzungszone kandidieren könnte, immer noch Wähler anziehen würde. Auch in der Kontroverse um einen zentralistischen oder föderalistischen Aufbau des deutschen Staates versuchte OIR wieder zu vermitteln und führte aus, daß ein gewisses $\mathrm{Maß}$ an Zentralisierung auf Zonenebene - einerseits in der anglo-amerikanischen Bizone, andererseits in der sowjetischen Zone schließlich bereits erfolgt sei. In diesem Zusammenhang wiederholte OIR das Argument, daß die Tendenz zur Zentralisierung in einem modernen Staat letztlich unvermeidlich sei, und erneut wurde versichert, daß in einer weitgehend zentralistischen Struktur nicht unbedingt ein Hindernis für die Demokratisierung Deutschlands gesehen werden müsse.

Insgesamt werfen die in diesen Studien vorgetragenen Positionen ein bezeichnendes Licht auf die Haltung der Abteilung im Kalten Krieg: Während in der Frage der Parteienzulassung die Sowjetunion als inflexibel und nicht kompromißbereit erschien, waren es in der Zentralismus-Föderalismus-Kontroverse die USA, die zu wenig flexibel auf einem Standpunkt beharrten, der, zumindest nach Ansicht von OIR, nicht einmal ihren politischen Interessen entsprach ${ }^{75}$. Bei aller Intransigenz, die auch OIR-Studien der Sowjetunion immer wieder bescheinigten, bestand man in der Abteilung darauf, den sich zunehmend ausprägenden Antagonismus zwischen Ost und West als „Gemeinschaftsproduktion" der beiden Großmächte zu interpretieren. Besonders illustrativ ist in diesem Zusammenhang eine OIR-Studie, deren irreführender Titel - „The Effects of the Soviet Occupation on German Unity “76 - „kalten Kriegern“ in Washington Argumentationshilfen versprach, die ihnen freilich nicht geboten wurden. Statt dessen bemühte sich OIR um ihre „Umerziehung": Fast schon schematisch wurde die Entwicklung des Ost-West-Antagonismus als gewissermaßen negativ komplementärer Prozeß dargestellt, in dem sich die einzelnen, auseinanderstrebenden Schritte ergänzten und zu einer Auseinanderentwicklung führten, an der keine Seite die "Schuld" trug. Denn wie schon in der Studie zur "Implementation of the Potsdam Declaration "77 erschien die in Pots-

73 NA, RG 59, OIR/(R\&A) 4514, „Territorial Questions in Germany: Background and Documentation“, 17.10. 1947; NA, RG 59, OIR/(R\&A) 4515, "Transfers of Population in Germany: Background and Documentation“, 28.10. 1947; NA, RG 59, OIR/(R\&A) 4523, „Political Parties in Germany: Background and Documentation“, 17.10. 1947; NA, RG 59, OIR/(R\&A) 4525, „German Central Government: Background and Documentation“, 17.10. 1947; alle Studien sind als „Preliminary Version“ gekennzeichnet.

${ }^{74}$ Dazu oben VIII., 1. Teil.

75 Vgl. oben VIII., 1. Teil, NA, RG 59, OCL/(R\&A) 3782, „Centralism and Federalism in Germany", 1.11. 1946.

76 NA, RG 59, OIR/(R\&A) 4776, 2.11. 1948.

77 Dazu oben VIII., 1. Teil. 
dam vereinbarte Demokratisierung Deutschlands nur „as a common Allied objective“ als ein Ziel, das man an diesem gemeinsamen Ausgangspunkt nicht genauer lokalisiert hatte, ganz zu schweigen von einer Verständigung darüber, wie es am besten zu erreichen wäre. Wieder führte OIR aus, daß die USA und die Sowjetunion aufgrund ihres unterschiedlichen, aus ihren jeweiligen Traditionen und „Weltanschauungen“ erwachsenden Demokratieverständnisses ganz unterschiedliche - im buchstäblichen Sinne divergierende - Vorstellungen darüber entwickelten, wie dieses „common Allied objective“ am besten zu erreichen sei, so daß sie fast unvermeidlich auch ganz verschiedene "Ziele" erreichten:

"To the Soviet authorities, democratization meant destruction of the basis of the traditional ,imperialist' groups by the introduction of fundamental changes in the social and economic structure [...] In the Western view, democratization meant replacement of the Nazi structure of government and political life by liberal democratic procedures and institutions, after which the German people would be permitted to decide on any specific social or economic change. The result of the introduction of the liberal democratic procedures in the West was the re-establishment of the traditional pattern of German society, whereas in the East a new social pattern was built up with little regard for democratic forms and procedures." Vor diesem Hintergrund war die Spaltung Deutschlands für OIR "the result of the Soviet policy of establishing a semi-socialist, authoritarian system in the Soviet Zone and the divergent Western Allied policy of reconstructing Germany according to the traditional pattern of Western democracy“.

In ähnlicher Weise, aber doch mit einer deutlichen Akzentverschiebung zu Lasten der Sowjetunion, in der die kritische Beurteilung der sowjetischen Reparationspolitik anklang ${ }^{78}$, wurde auch die nicht verwirklichte Behandlung Deutschlands als wirtschaftliche Einheit als Konsequenz der negativ komplementären Politik beider Seiten dargestellt: „Economic unification of Germany was made impossible by the Soviet authorities when they insisted on retaining trade controls and taking reparations from current production in their zone. The economic merger of the Western zones and the separate currency reforms in the East and West completed the split."

Daß man in OIR trotz dieser weitgehend „neutralen“ Darstellung der Entwicklung des Ost-West-Gegensatzes immer weniger Sympathien für die sowjetische Politik hegte, wird gleichwohl eindeutig: Dem Verständnis für die sowjetischen Positionen als durch ein historisch gerechtfertigtes Sicherheitsbedürfnis und prinzipiell, wenn auch nicht notwendigerweise im einzelnen, legitime nationale Interessen motiviert, steht eine Darstellung der sowjetischen Besatzungspolitik gegenüber, die so negativ ist, daß die von OIR postulierte „Gleichberechtigung“ bzw. die implizierte Überlegenheit der sowjetischen Demokratisierungskonzeption in Frage gestellt wird. So entsprach zumindest die Beschreibung der Situation in der "Ostzone“ dem, was man von einem Bericht einer US-Behörde über die Auswirkungen der sowjetischen Besatzung Ende 1948 erwarten mochte: Der Aufbau neuer gesellschaftlicher Strukturen sei unter weitgehender Mißachtung demokratischer Prozesse erfolgt; die sowjetische Militäradministration mische sich ständig in die Angelegenheiten der Parteien ein; das Parteiensystem sei durch die uneingeschränkte Vormachststellung der SED charakterisiert, deren Hand-

${ }^{78}$ Siehe oben S. $244 f$. 
lungsspielraum freilich auch eng begrenzt sei, da sie als „chief instrument for carrying out Soviet occupation objectives“ diene ${ }^{79}$. Gewerkschaften und Bauernverbände seien ebenfalls vollständig instrumentalisiert worden; Regierung und Verwaltung seien zentralisiert und lägen zwar in deutscher Hand, doch hätten gewählte Körperschaften keinerlei Kontrolle über die zentralen Behörden, die Marionetten der sowjetischen Militäradministration und der SED seien. Die Verfassungen garantierten zwar Grundrechte, doch gebe es keine Rechtssicherheit, und die Polizei übe zahlreiche Funktionen aus, "which are not consistent with democratic government". Bildungswesen und Medien seien ebenfalls in den Dienst des Systems gestellt worden, um die Bevölkerung politisch $\mathrm{zu}$ indoktrinieren.

Diese überaus negative Darstellung der sowjetischen Besatzungspolitik dürfte als Hinweis darauf anzusehen sein, daß man sich in OIR inzwischen in dem Verdacht, der in der Studie zur Reparationspolitik der Sowjetunion angeklungen war, bestätigt fühlte: Der Sowjetunion schien es nicht so sehr um den Aufbau einer deutschen Demokratie als vielmehr um die Sicherung ihres Einflusses und ihrer wirtschaftlichen Interessen zu gehen. Darin mochte sich freilich nur ein ähnlicher Wandel der der sowjetischen Deutschlandpolitik zugrundeliegenden politischen Voraussetzungen ausdrükken, wie ihn Kindleberger für die amerikanische Politik beschrieb: „The German policy of the United States immediately after unconditional surrender was in large measure based on [.. .] the attempt to find a basis of accommodation with the Soviet Union. [...] Two years of frustration in attempting negotiation with the Soviet Union have produced in many quarters an attitude of mind based almost solely on [...] the attempt to secure strategic advantages to improve our chances of winning a possible war with the USSR.“ ${ }^{80}$

Die Vorstellung, daß dies auch umgekehrt für die Sowjetunion gelten könnte, mag hinter der konsequent durchgehaltenen Gegenüberstellung der in einer Vertiefung der Spaltung Deutschlands resultierenden sowjetischen und amerikanischen Schritte stehen. Der Beantwortung der Frage nach der „Schuld“ am Kalten Krieg schien sich OIR mithin hartnäckig zu verweigern - Partei ergriff die Abteilung dennoch: Bei aller Kritik an den Konzeptionen und der Durchführung der US-Politik in einzelnen Bereichen und bei aller Kritik an ihren Ergebnissen ließ OIR keinen Zweifel daran, daß man in der Abteilung die Instrumente der amerikanischen Besatzungspolitik - demokratische Institutionen und Strukturen - im Prinzip für die richtigen hielt. Das änderte nichts daran, daß man mit Franz Neumann der Meinung war, daß auch die amerikanische Politik keine Demokratie in Deutschland begründet hatte - freilich sah man in OIR die Verantwortung dafür nicht nur bei der Militärregierung.

\footnotetext{
79 NA, RG 59, OIR/(R\&A) 4676, „Recent Changes in the German Party System“, 16.8. 1948.

80 „Excerpts from the Cleveland-Moore-Kindleberger Memorandum “, in: Kindleberger, Marshall Plan Days, S.3-24, Zitat S.12f. Die bei Kindleberger abgedruckten Auszüge dieser keineswegs trocken formulierten Denkschrift des ehemaligen R\&A-Mitarbeiters, der inzwischen in der Division of German and Austrian Economic Affairs des State Department tätig war, bieten eine scharfe Kritik an der amerikanischen Besatzungspolitik in Deutschland und einen interessanten Einblick in das in Washington herrschende politische Klima der "Marshall Plan Days“.
} 


\section{Eine „falsche Theorie der Demokratie“ in der Praxis?}

Angesichts der sich abzeichnenden Westintegration rückte für OIR seit Ende 1947 erneut die Frage in den Vordergrund, wie das demokratische Potential und die demokratische "Reife“ Deutschlands bzw. Westdeutschlands einzuschätzen seien. In einer der Studien, die um diese Zeit wohl in Vorbereitung der für Ende November geplanten fünften Außenministerkonferenz entstanden, erörterte OIR zunächst einmal mehr, welche Faktoren eine stabile Demokratie in Deutschland garantieren könnten, und argumentierte in diesem Zusammenhang: „[It $]$ should not be thought that federalization alone offers a guarantee for a peaceful, democratic Germany. Such guarantees must be sought elsewhere in a combination of external controls, changes in Germany's social structure and psychology, and the integration of Germany into a reactivated Europe. ${ }^{\circ 1}$

Das erste Element dieser „Kombination“ bezog sich offenbar auf einen noch auszuhandelnden Friedensvertrag oder eine vergleichbare Regelung, die im Falle der Gründung eines deutschen Staates notwendig schien; das letztgenannte Element konnte dagegen durch die Einbeziehung Westdeutschlands in das Europäische Wiederaufbauprogramm als bereits abgedeckt gelten. Als Frage blieben mithin die für notwendig gehaltenen „changes in Germany's social structure and psychology“. Erstere zu bewirken, wäre nach den von R\&A im Rahmen der Arbeit an den Civil Affairs Guides entwickelten Konzeptionen ganz wesentlich Aufgabe der Entnazifizierung gewesen ${ }^{82}$. Ihre erfolgreiche Durchführung mußte zugleich als unerläßliche Voraussetzung für die „changes in psychology“ erscheinen, die gerade die Amerikaner mit ihren Bemühungen um eine "reeducation“ der Deutschen anstrebten ${ }^{83}$. Insofern verdient ein umfassender Bericht zum „Present Status of Denazification in Western Germany and Berlin ${ }^{\text {"84, }}$, den OIR Mitte April 1948 vorlegte, besonderes Interesse. Diese Bilanz ist auch deshalb interessant, weil sie deutlicher als die meisten anderen der nach 1945 entstehenden Berichte das Gegenbild der von R\&A entwickelten Konzeptionen als Bewertungsmaßstab erkennen läßt.

${ }^{81}$ NA, RG 59, OIR/(R\&A) 4525, Preliminary Version, „German Central Government: Background and Documentation“, 17.10.1947.

82 Vgl. dazu oben V., 1. Teil.

${ }^{83}$ Vgl. dazu NA, RG 59, OIR/(R\&A) 4237-R (PV), "The Progress of Reeducation in Germany", 10.11. 1947; eine offensichtlich längere, frühere Version vom 3.6. 1947 auszugsweise in deutscher Übertragung bei Söllner (Hrsg.), Archäologie der Demokratie, Bd.2, S.177-216. Vgl. in diesem Zusammenhang auch Tent, Mission on the Rhine, sowie Pronay/Wilson (Hrsg.), The Political Re-education of Germany; vgl. auch den bereits genannten Artikel Neumanns zu diesem Thema in Commentary 3/6 (1947), S.517-525, bzw. Neumann, Wirtschaft, Staat, Demokratie, S. 290-308.

84 NA, RG 59, OIR/(R\&A) 4626, „The Present Status of Denazification in Western Germany and Berlin“, 15.4. 1948; in deutscher Übersetzung gekürzt bei Söllner (Hrsg.), Archäologie der Demokratie, Bd.2, S. 217-249. Vgl. auch den Aufsatz von Herz (Mitarbeiter der German Section der Central European Branch in der Division of Research for Europe des OIR, siehe dazu Department of State, Register, April 1, 1948, S.76), The Fiasco of Denazification, in: PSQ 63/4 1948, S. 569-594; wie die weitgehende Übereinstimmung von Material und Interpretation nahelegt, dürfte Herz an der Abfassung des OIR-Berichts beteiligt gewesen sein, zumindest muß er ihn aber für seinen eigenen Artikel benutzt haben. Vgl. außerdem ders., Denazification and Related Policies, in: ders. (Hrsg.), From Dictatorship to Democracy, S. 15-38. 
Den von R\&A entworfenen Richtlinien zur Entnazifzierung hatte die Vorstellung zugrunde gelegen, daß das NS-Regime von einer aus den Spitzen von Partei, Wirtschaft, Militär und Bürokratie zusammengesetzten Herrschaftselite getragen wurde, die es als Vorbedingung für eine Demokratisierung Deutschlands zu eliminieren gelte. Obwohl diese an gewissermaßen qualitativen Kriterien orientierte Konzeption später durch die eher quantitativ operierende - nämlich praktisch alle Erwachsenen erfassende - „Fragebogenaktion" der US-Militärregierung überlagert wurde ${ }^{85}$, erklärte OIR die Beobachtung, daß die Entnazifizierung von Anfang an eines der am heftigsten diskutierten Themen in der sich wiederbelebenden deutschen Politik gewesen sei, bezeichnenderweise mit einem impliziten Verweis auf die Zielrichtung der von R\&A vertretenen Konzeption. So führte OIR aus, daß es unvermeidlich gewesen sei, "that the major parties and social groups should clash violently over a procedure which, if energetically implemented, might have led to a transformation of Germany's social and economic structure and to a thorough change in its educational institutions and cultural orientation".

Während hier scheinbar angedeutet wird, daß die Entnazifizierung nicht energisch genug betrieben worden sei, wird andererseits zumindest mit Blick auf die amerikanische Zone festgestellt, daß die Militärregierung im ersten Jahr eine recht gründliche Säuberung im politischen und administrativen Bereich sowie in leitenden Wirtschaftspositionen durchgeführt habe. Die angewandten Kriterien seien zunächst allerdings „rigid and mechanical“ gewesen, doch sei das Vorgehen flexibler geworden, nachdem mit dem Gesetz zur Befreiung von Nationalsozialismus und Militarismus die Verantwortung an deutsche Behörden und Ausschüsse übergeben worden war. Die Ausschüsse hätten sich allerdings vornehmlich mit „minor or nominal Nazis* befaßt, von denen den meisten nur geringfügige Geldbußen auferlegt worden seien, während man schwerere Fälle meist zurückgestellt habe. Daß die Militärregierung dann ihrerseits begann, Vorschriften immer mehr abzumildern, habe letztlich dazu geführt, „that at a time when most of the major Nazis were still to be tried the huge majority of them were downgraded to lower categories and thus escaped the more serious sanctions and employment restrictions“.

Ganz ähnliche Ergebnisse waren nach Darstellung von OIR für die britische Zone zu verzeichnen, wo die Entnazifizierung allerdings von vornherein mit weitaus weniger Ehrgeiz und Entschlossenheit betrieben worden sei, um bereits Anfang 1948, gerade als sie in deutsche Verantwortung übergehen sollte, eingestellt zu werden. In der französischen Zone habe man sich zunächst darauf beschränkt, ehemalige NS-Amtsinhaber mit Geldbußen zu belegen oder ihre Versetzung oder Entlassung anzuordnen. Die Anfang 1947 beschlossene Übernahme der Regelungen der amerikanischen Zone sei weitgehend ohne Konsequenzen geblieben, da es nicht gelungen sei, ein entsprechendes System aufzubauen. In Berlin erfolge die Entnazifizierung noch immer nach den Richtlinien der zu Beginn der Besatzung erlassenen Verfügung der Kommandantur und beschränke sich so auf die Bestätigung oder Entlassung von Stelleninhabern. Dieser Prozeß sei extrem langsam und rigide, und die Entscheidungen reflektierten nicht selten „political bias and pressures prevailing in the different occupation sectors“.

${ }^{85}$ Eine ausführliche Darstellung der amerikanischen Entnazifizierungspolitik und -praxis findet sich bei Niethammer, Die Mitläuferfabrik; vgl. außerdem Dorn, Inspektionsreisen in der USZone, S. $88 \mathrm{ff}$. 
Nach dieser wenig positiven Bilanz wandte sich OIR der von deutscher Seite geäußerten Kritik an der Entnazifizierung zu. Nach Ansicht der Abteilung ließen sich die kritischen Stimmen ursprünglich zwei deutlich unterscheidbaren gesellschaftlichen und politischen Gruppen zuordnen: Als zu hart, ungerecht und unvereinbar mit persönlichen Freiheitsrechten und demokratischen Grundsätzen sei die Entnazifizierung vor allem in politisch rechtsstehenden Kreisen kritisiert worden, während die Linke die Entnazifizierung grundsätzlich befürwortet habe, ihre praktische Durchführung aber als zu lasch und letztlich ungerecht kritisierte.

In rechten Kreisen habe man zunächst die von der Militärregierung durchgeführte Entnazifizierung als zu inflexibel und mechanistisch kritisiert. Nachdem mit dem Gesetz zur Befreiung von Nationalsozialismus und Militarismus deutsche Ausschüsse mit der Durchführung der Entnazifizierung betraut worden waren, habe man begonnen, die Entnazifizierung als zu umfassend zu kritisieren ${ }^{86}$. Als dieser Kritik durch Gesetzesänderungen Rechnung getragen wurde, habe sich die Kritik grundsätzlich gegen die Entnazifizierung gerichtet, die nun als Bruch von Rechtsgrundsätzen dargestellt wurde, der nur geeignet sein könne, das Vertrauen der Deutschen in demokratische Prinzipien zu untergraben.

Die Linke habe die Entnazifizierung zunächst befürwortet, dann aber zunehmend bemängelt, daß die Art ihrer praktischen Durchführung die „kleinen“ Nazis gegenüber den „major Nazis" in mehrfacher Hinsicht benachteilige: Zum einen träfen gewisse Sanktionen wie vorläufige Arbeitsverbote die Masse der „kleinen“ Nazis weitaus härter, zum anderen sei diese Gruppe zuerst „entnazifiziert" worden, während Verfahren gegen schwerer belastete Personen oft zurückgestellt wurden, so daß diese schließlich in den Genuß von Herabstufungen und abgemilderten Bestimmungen gekommen seien.

Wie OIR ausführte, hatte die Milderung von Vorschriften und Verfahren überdies die Befürworter der Entnazifizierung in die Defensive gedrängt. Während es anfangs sowohl in der CDU wie in den Kirchen Gruppen gegeben habe, die für eine konsequente Säuberung eintraten, hätte sich dies angesichts der weitverbreiteten Opposition gegen die Entnazifizierung bald geändert. Nachdem die Verantwortung in deutsche Hände übergegangen war, sei jegliche Identifizierung mit dem Entnazifizierungsprogramm zunehmend als „political liability“ betrachtet worden, während seine Ablehnung als „political advantage“ erschien. Vor diesem Hintergrund hätten sich die rechten Parteien und die Kirchen zu den Hauptprotagonisten einer immer aggressiveren Kampagne gegen die Entnazifizierung entwickelt, an der sich in zunehmendem Maße auch die Linke beteilige.

Die Frage, ob und inwieweit die an der Entnazifizierung geäußerte Kritik gerechtfertigt sei, ließ sich nach Ansicht von OIR nur schwer genau beantworten. Gleichzeitig wurde jedoch darauf verwiesen, daß sich schon allein in den von der Presse berichteten Fällen zahlreiche Hinweise darauf fänden, daß Kritik an ungerechtfertigt milden Urteilen oft berechtigt sei ${ }^{87}$; zudem sei eindeutig nachzuweisen, daß die Arbeit der

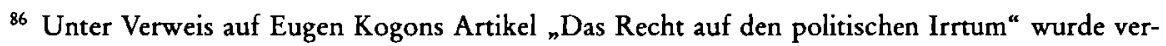
merkt: "This criticism borrowed a concept from a staunch anti-Nazi."

${ }^{87}$ OIR belegte dies und die folgenden Aussagen mit einer umfassenden "Presseschau“ deutscher Zeitungen, die sich weitgehend identisch auch bei Herz, Fiasco of Denazification, in: PSQ 63/4 1948, S. $581 \mathrm{ff}$. findet. Fast schon kurios ist, daß ein späterer OIR-Bericht (NA, RG 59, OIR/(R\&A)) 4997, „The Denazification Program in the US Zone of Germany“, 27.12. 1949) auf diesen Artikel von Herz als Beleg verweist. 
Spruchkammern durch Druck - bis hin zur Bedrohung von Ausschußmitgliedern und Zeugen - erschwert werde und sich die Beweisführung oft schwierig gestalte, da Belastungszeugen nur schwer aufzufinden seien, während es vor allem einflußreichen Personen oft gelänge, sich „Persilscheine ${ }^{\text {“ }}$ zu verschaffen. Darüber hinaus gebe es Anzeichen für "positive ill-will on the part of German authorities charged with carrying out the program“. Andererseits ließen sich praktisch keine Hinweise darauf finden, daß Angeklagte unangemessen hart oder unfair behandelt würden. Dieser Vorwurf sei nur insofern berechtigt, als nicht selten ,kleine“ Nazis im Vergleich mit schwerer belasteten Personen zu hart bestraft worden seien; letztere entzögen sich den Prozessen oft erfolgreich oder erhielten milde Urteile, die oft mit widersprüchlichen Argumenten begründet würden.

Diese Entwicklung sei zwar - wie nicht ohne ironischen Unterton vermerkt wurde „salutary for the administrative continuity of public life ${ }^{\text {, }}$, berge aber andererseits auch gewisse Gefahren. Die Abteilung wollte nicht ausschließen, daß sich die Entlassung von "major Nazis“ aus der Internierung als Bedrohung für die Sicherheit der Alliierten erweisen könne, zumal unter den Entlassenen „a considerable number of trained activists and terrorists“ zu vermuten sei. Als problematisch betrachtete OIR auch den aus neueren Statistiken hervorgehenden Sachverhalt, „that [.. .] a considerable number of former Nazis remain in the bureaucracy, particularly in what is called the higher civil service“. So zeige etwa ein Bericht der Militärregierung für die US-Zone, daß 50$60 \%$ der Richter und Staatsanwälte ehemalige NSDAP-Mitglieder seien; ähnliche Zahlen gebe es für die britische Zone. Die kommunistische und sowjetische Propaganda könne sich dies zunutze machen; zudem sei nicht auszuschließen, daß dies zur Sabotage des demokratischen Prozesses führen könnte. Bedenklich sei auch, daß die CDU einen hohen Anteil an ehemaligen Nazis in ihrer Anhängerschaft hätte; allerdings werbe die Linke ebenfalls um die Gunst dieser Wähler. Nach Ansicht der Abteilung waren überdies negative Auswirkungen auf die politische „Moral“ der Deutschen nicht auszuschließen, wenn Nazis, die Verbrechen begangen hätten, nicht verfolgt würden, denn, so wurde argumentiert, "totalitarian crime thus appears to escape retribution".

Bezeichnenderweise hielt es OIR abschließend für notwendig zu erörtern, welche Gegenmaßnahmen möglich seien, wobei ausnahmsweise - wenn auch eher zurückhaltend - Empfehlungen ausgesprochen wurden ${ }^{88}$. Wie ausgeführt wurde, mochte es angesichts der Mängel der bisherigen Entnazifizierungspraxis und der sich daraus ergebenden Gefahren zwar erstrebenwert erscheinen, nochmals mit neuen und einheitlichen Richtlinien in den drei Westzonen eine "Nachbesserung“ der Entnazifizierung zu versuchen, doch müsse dies wohl als impraktikabel betrachtet werden. Realistisch und empfehlenswert sei aber ein begrenzteres Vorgehen: So könnten Inhaber bestimmter eng definierter Schlüsselpositionen des öffentlichen und kulturellen Lebens entweder direkt von der Militärregierung oder unter ihrer Kontrolle überprüft werden; darüber

${ }^{88}$ Seit der Übernahme durch das State Department war man in der Abteilung gezwungen, weitaus strenger als früher darauf zu achten, daß man mit expliziten (und impliziten) „policy recommendations" keine traditionellen Kompetenzen verletzte. Ab 1949 trugen OIR-Berichte dann auf der Titelseite den Vermerk: „This is an intelligence research report; nothing in it is to be construed as a statement of U.S. or Departmental policy or as a recommendation of any given policy. ${ }^{\alpha}$ In den fünfziger Jahren gab es schließlich sogar entsprechend vorgedruckte Titelblätter. 
hinaus könne die Militärregierung auf einer energischen Verfolgung von NS-Verbrechern durch die deutsche Justiz bestehen und diese unterstützen ${ }^{89}$.

Insgesamt ließ diese Bilanz der Entnazifizierung kaum Zweifel daran, daß die wohl ehrgeizigste und aufwendigste Demokratisierungsstrategie der amerikanischen Besatzungspolitik nicht nur als politische Säuberung, sondern vor allem auch als Instrument einer Demokratisierung als gescheitert gelten mußte. Aus der OIR-Studie war auch bereits zu entnehmen, was zeitgeschichtliche Detailforschung erst nach mehr als zwei Jahrzehnten „Verdrängung“ wieder ans Licht befördern sollte: daß sich die Entnazifizierung in der Praxis weitgehend auf die Rehabilitierung der Masse der „Mitläufer" beschränkte, zu denen in Folge der Neueinstufungen schließlich auch zahlreiche ehemals durchaus „aktive“ Nazis gerechnet wurden" ${ }^{90}$. Während dies nach Darstellung von OIR vor allem darauf zurückzuführen war, daß man sich nicht an qualitativen Kriterien orientierte, sondern den Ehrgeiz entwickelte, alle Erwachsenen zu erfassen, und eben deshalb gezwungen war, die nicht zu bewältigende Zahl der Fälle durch Amnestien und Neueinstufungen zu reduzieren, wurde in dem OIR-Bericht auch deutlich, daß gerade die Entnazifizierung der Bereich war, in dem sich „alliierte Fehler" und „deutsche Mängel“ ergänzten"1.

Interessant ist in diesem Zusammenhang, daß die von OIR vorgeschlagenen Maßnahmen letztlich ein Plädoyer für die fortgesetzte Kontrolle der Deutschen durch die Militärregierung beinhalten. Ganz offensichtlich schätzte man den Willen der Besatzungsmacht zur „Befreiung“ der Deutschen von „Nazismus und Militarismus“ bei aller Kritik an ihrer Politik höher ein als den der Deutschen, die, wie in der OIR-Studie anklang, ihre versuchte „Befreiung“ als kränkende und ungerechte Bestrafung für einen doch zutiefst menschlichen „politischen Irrtum“ zu betrachten schienen ${ }^{92}$.

Wie gering das Interesse der Deutschen an einer "Selbstreinigung“ und damit an einem möglichst wenig kompromittierten demokratischen Neuanfang war, zeigte sich nach Darstellung von OIR nicht zuletzt auch an der in den Universitäten geübten Entnazifizierungspraxis ${ }^{93}$. OIR konzedierte allerdings, daß die Entnazifizierung in diesem Bereich besonders problematisch sei, denn: „even when they had not joined Nazi organizations, many German professors had placed their great prestige at the service of the Nazis by passive acceptance of Nazi practices." Die Militärregierung habe die Entnazifizierung an den Universitäten an politisch akzeptable Fakultätsausschüsse übertragen; wie OIR fast schon verständnisvoll meinte, zeigten diese eine natürliche

${ }^{89}$ Vgl. dazu Broszat, Siegerjustiz oder strafrechtliche "Selbstreinigung ${ }^{“}$, in: VfZ 29/4 (1981), S. 477-544.

90 Niethammers Darstellung Die Mitläuferfabrik erschien erstmals 1972 unter dem Titel Entnazifizierung in Bayern. - Bezeichnend ist in diesem Zusammenhang im übrigen, daß sowohl in der OIR-Studie wie in dem Artikel von Herz notiert wird: „Nothing could be more revealing than the strange modification of meaning that the term, denazification' itself has undergone. While at first signifying the elimination of Nazis from public life, it has now in German everyday language come to mean the removal of the Nazi stigma from the individual concerned, that is, the procedure by which he gets rid of certain inhibitions or restrictions (,Mr. X was denazified yesterday ${ }^{\text {- }}$ he can now take up his former profession again). "Zit. nach Herz, Fiasco of Denazification, in: PSQ 63/4 1948, S. 590 (Anmerkung 108).

${ }^{11} \mathrm{Vgl}$. dazu den oben Anmerkung 3 zitierten Artikel von Eugen Kogon.

92 Vgl. dazu Buscher, U.S. War Crimes Trial Program, S. $109 \mathrm{f}$.

${ }^{93}$ NA, RG 59, OIR 4237-R (PV), "The Progress of Reeducation in Germany", 10.11. 1947. 
Neigung zur Milde gegenüber ihren Kollegen. Letztlich habe sich die Militärregierung deshalb gezwungen gesehen, zusätzliche Säuberungen vorzunehmen, wobei an der Universität München weitere 33 Entlassungen von Fakultätsmitgliedern, in Erlangen 76 Entlassungen von Fakultäts- und Verwaltungspersonal als notwendig erachtet wurden.

Der „passive Widerstand“ und die vehemente Kritik, die die amerikanischen Bemü-

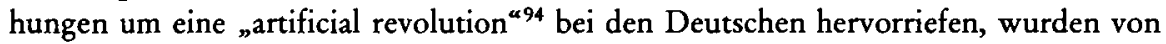
OIR als bestürzende Indizien für den Mangel an demokratischem Potential in Deutschland gewertet. So schwer sich R\&A mit den sozialpsychologischen Grundlagen des Nationalsozialismus getan hatte, so schwer taten sich nun die R\&A-Nachfolgeorganisationen im State Department mit denen der „Zusammenbruchgesellschaft": Deren Weigerung, sich mit der eigenen jüngsten Vergangenheit auseinanderzusetzen, wurde in OIR ausschließlich als Ausdruck einer besorgniserregenden Kontinuität autoritären, antidemokratischen und nationalistischen Denkens gewertet.

Von dieser Bilanz zur Entnazifizierung scheint so eine direkte Linie zu Berichten zu führen, in denen OIR die deutschen Parteien und die politischen Tendenzen im Jahr vor der Gründung der Bundesrepublik beobachtete, um zu zutiefst pessimistischen Schlußfolgerungen zu gelangen.

So stellte die Abteilung in einer Analyse der „Recent Changes in the German Party System "95 einleitend zwar zunächst fest, daß sich die politischen Parteien beim Aufbau der von den Besatzungsmächten gewünschten demokratischen Institutionen als unabkömmlich erwiesen hätten, doch wurde unter Hinweis auf die noch immer bestehende Prärogative der Besatzungsmächte sogleich davor gewarnt, daraus auf die feste Verankerung demokratischer Institutionen und Strukturen in der politischen Kultur "post-Nazi“-Deutschlands zu schließen: „This outward appearance of political life in post-Nazi Germany is deceptive. Though the parties are invested with all the paraphernalia of normal political activities, they operate under specifically limited conditions creating a peculiarly artificial and synthetic situation."

Die Politiker benutzten das System der "dual authority“, die durch das Nebeneinander von fortbestehender Besatzungsherrschaft und der wiederhergestellten deutschen Regierungs- und Verwaltungsstruktur gegeben sei, um sich offener Verantwortung für politische und administrative Entscheidungen soweit wie möglich zu entziehen. Gleichzeitig übernähmen sie aber zunehmend offener die Rolle als Verteidiger nationaler deutscher Interessen gegenüber den Besatzungsmächten. Die deutsche Bevölkerung habe bislang allerdings nur wenig Interesse für die Politik der verschiedenen Parteien

94 Die These, daß die amerikanische Besatzungspolitik eine kontrollierte, „künstliche Revolution “ anstrebte, hat Montgomery vertreten, in: Forced to Be Free. The Artificial Revolution in Germany and Japan.

95 NA, RG 59, OIR/(R\&A) 4676, 16.8. 1948; deutsch bei Söllner (Hrsg.), Archäologie der Demokratie, Bd.2, S.258-285. Interessant ist der Vergleich dieser Studie mit dem 1948 publizierten Aufsatz Neumanns, Military Government and the Revival of Democracy, deutsch in: ders., Wirtschaft, Staat, Demokratie, S. 309-325, in dem die wichtigsten Themenpunkte der OIR-Studie ebenfalls angesprochen und - angesichts dessen, daß Neumann OIR Anfang 1947 verlassen hatte - bemerkenswert ähnlich erörtert und beurteilt werden. Auffällige Ähnlichkeit mit dieser und anderen OIR-Studien zeigt allerdings auch ein von Holborn Anfang 1948 im Auftrag des State Department verfaßter „Bericht zur deutschen Frage“, in: Hahn, Hajo Holborn, Bericht zur deutschen Frage, in: VfZ 35 (1987), S. 135-166. 
gezeigt; die meisten seien mit ihren persönlichen Problemen vollauf beschäftigt und tendierten dazu, Politiker als Handlanger der jeweiligen Besatzungsmacht zu sehen und ihnen mit Mißtrauen zu begegnen.

Wie schon in früheren Berichten wurde das politische Leben in Deutschland auch hier wieder als „künstlich“ beschrieben, doch schien diese Künstlichkeit nun eine andere Qualität anzunehmen: Sie wurde nicht länger vor allem durch Zonenaufteilung und Besatzungsherrschaft erklärt, sondern ergab sich aus der Gegenüberstellung des von den Besatzungsmächten forcierten Aufbaus demokratischer Institutionen - für den sich Parteien und Politiker zwar als unabkömmlich erwiesen, doch für den sie gleichzeitig keine politische Verantwortung übernehmen wollten - und dem zunehmend engagierteren Eintreten für nationale deutsche Interessen gegenüber den Besatzungsmächten von seiten derselben Politiker. Dazu kam die weiterbestehende Apathie der Bevölkerung, deren politisches Interesse auch durch eine so zentrale Maßnahme wie die Wiederherstellung eines Mehrparteiensystems nicht zu wecken war. Insgesamt schien damit impliziert, daß diesem an sich demokratischen System seine demokratische Basis fehlte.

Das von OIR gezeichnete Bild der Parteien selbst gab überdies wenig Anlaß zu der Hoffnung, daß in ihnen vielleicht dennoch demokratische Energien gebündelt sein könnten. Die bürgerlichen Parteien waren nach Darstellung der Abteilung - zusammen mit der "new bureaucracy", die weiterhin als der traditionelle, vorgeblich "unpolitische“ Vertreter von Interessen des Bürgertums und der Rechten fungiere - „strongly entrenched in the bizonal administration as well as in the governments of most of the Länder". Sie übten auf regionaler Ebene starken Einfluß bei der Regelung wirtschaftlicher und gesellschaftlicher Fragen aus und hätten sich zumindest vorläufig gegen die Linke in den Kontroversen um die Sozialisierungsklauseln der Länderverfassungen sowie die Kompetenzen der Betriebsräte durchgesetzt. Als ihr bislang wichtigster Erfolg müsse allerdings die Verwässerung des Entnazifizierungsprogramms betrachtet werden, denn, wie OIR trocken bemerkte: „This was the issue in which they had the biggest stake, since the majority of their followers were affected by it."

Die programmatischen Konzeptionen der bürgerlichen Parteien befänden sich noch in Entwicklung. Die gemäßigten Parteien, insbesondere die CDU, sähen sich wachsender Konkurrenz von seiten extremistischer nationalistischer oder partikularistischer Splittergruppen ausgesetzt. Deren politische Agitation fände zunehmend Unterstützung beim verarmten mittleren Bürgertum und den Millionen von Flüchtlingen. Die SPD könne sich noch immer auf die loyale, wenn auch wenig enthusiastische Anhängerschaft der Arbeiter verlassen und verfüge zudem - im Gegensatz zu den Jahren vor der nationalsozialistischen Machtübernahme - in der Person Kurt Schumachers über einen „outstanding leader“. Programmatisch hätten die Sozialdemokraten weitgehend auf traditionelle Positionen zurückgegriffen, wobei allerdings versucht worden sei, durch eine "Liberalisierung" des Programms Teile des Bürgertums zu gewinnen. Dem sei wenig Erfolg beschieden gewesen, so daß OIR insgesamt glaubte konstatieren zu können: „Both organizationally and ideologically, this party is more and more reverting to its pre-war position as representative of the majority of the working class within the framework of a democratic and anti-totalitarian political order." Die Kommunistische Partei im Westen genieße zwar noch immer Unterstützung bei Teilen der Arbeiterschaft, doch sei es ihr nicht gelungen, aus ihrer Opposition gegen die West- 
mächte politisches Kapital für den Aufbau einer stärkeren Bewegung zu schlagen, denn: „The people have consistently rejected the CP because of its identification with Soviet policies."

Nach Ansicht von OIR mußte damit gerechnet werden, daß die Einrichtung eines westdeutschen Staates die politischen Konflikte zwischen den deutschen Parteien verschärfen würde. Ein wesentlicher Grund dafür sei, daß kaum zu erwarten stünde, daß die im Westen durchgeführte Währungsreform in absehbarer Zeit durch einen Ausgleich kriegsbedingter Lasten ergänzt würde, der die Erwartungen der Millionen von Ausgebombten und Flüchtlingen befriedigen könnte. Die daraus resultierende Unzufriedenheit werde die Tendenz zur Polarisierung des politischen Spektrums in eine extrem nationalistische und autoritäre Rechte einerseits und eine zahlenmäßig schwächere demokratische Linke andererseits beschleunigen; verschärfend komme hinzu, daß sich beide Gruppen wahrscheinlich einer zwar kleinen, aber gut organisierten Kommunistischen Partei gegenübersehen würden. So konnte OIR insgesamt nur eine düstere Perspektive für die deutsche Demokratie erkennen: „This [...] makes the chances for survival of constitutional government in Germany after the withdrawal of the occupation powers rather uncertain."

Der Pessimismus von OIR gründete sich neben dem Scheitern der Entnazifizierung und den nach Ansicht der Abteilung daraus resultierenden Konsequenzen - den kaum veränderten wirtschaftlichen und gesellschaftlichen Strukturen sowie der weiterwirkenden autoritären politischen Kultur - auf die Bedeutung, die die Abteilung den besonderen sozialen Problemen der Nachkriegszeit, darunter vor allem dem Flüchtlingsproblem, zumaß. Wie OIR in einer Studie zum „Refugee Problem in Western Germany“ ausführte ${ }^{96}$, mußte das Flüchtlingsproblem sowohl in seiner wirtschaftlichen Dimension wie auch in politischer und sozialer Hinsicht als überaus gravierend eingeschätzt werden. Besonders besorgniserregend war nach Ansicht der Abteilung der politische Sprengstoff, den diese Probleme bargen: „perhaps most dangerous politically is the economic plight of the refugees, which makes them vulnerable to the political extremism of both the Right and the Left, as well as the fact that so many refugees have been uprooted from their middle class economic foundation and now constitute a group similar to that which gave the Nazi Party its greatest support. The situation is full of political dynamite."

Nach Darstellung von OIR zeigten die deutsche Bevölkerung und in hohem Maße auch die Behörden wenig Neigung, Flüchtlinge zu integrieren; statt dessen sähen sich viele Flüchtlinge ständiger Diskriminierung ausgesetzt, und ihre Anerkennung als Staatsbürger mit allen Rechten hätten die Militärregierungen häufig gegen die lokalen Behörden durchsetzen müssen. Viele Deutsche wollten die Schuld und Verantwortung für das Flüchtlingsproblem den Alliierten zuschieben; sie wünschten, „to have these people return to their former homes", und sahen die Gelegenheit, „to shift the consequences of defeat onto another group“. Angesichts dieser Situation dürften die USA die Bedeutung des Flüchtlingsproblems in Westdeutschland nicht unterschätzen: „If ignored, it is likely to cause major disturbances in the social and political structure of Western Germany and would thus considerably retard Western Germany's pacification and integration into the Western orbit."

96 NA, RG 59, OIR/(R\&A) 4928, "The Refugee Problem in Western Germany", 16.5. 1949. 
Entsprechend düster fielen die Prognosen der Abteilung in einer Studie zur „Present Strategy and Strength of German Nationalism" aus". OIR ließ in dieser Arbeit keine Hoffnung für eine deutsche Demokratie: Weder ein „Wirtschaftswunder“ noch Westdeutschlands Integration in Europa, nicht einmal die Wiedervereinigung Deutschlands würden nach Ansicht der Abteilung verhindern können, daß in einem in die Selbständigkeit entlassenen Westdeutschland nationalistische Kräfte bald die Oberhand gewinnen und die von den Besatzungsmächten eingeführten demokratischen Institutionen und Verfahrensweisen zerstören würden. Daß dies für den Frieden in Europa und der Welt kaum Gutes verhieß, glaubte OIR nur in einem Nebensatz andeuten zu müssen.

Während die Befürchtung, daß sich in Deutschland wieder ein chauvinistisch-reaktionärer Nationalismus ausbreiten könnte, in vielen der seit 1947 entstandenen Arbeiten der Abteilung zu finden ist, schien sie in dieser Studie eine deutlich andere Qualität anzunehmen: OIR machte sich nun scheinbar eine Haltung zu eigen, die R\&A während des Krieges immer wieder zurückgewiesen hatte - nämlich die als „Vansittartism“ bekanntgewordene Überzeugung von dem angeborenen aggressiven Nationalismus der Deutschen $^{98}$. Implizit war damit ein leidenschaftliches Plädoyer für den Verbleib der Besatzungstruppen verbunden, denn die von der Abteilung entworfenen "worst case scenarios" waren erst nach der Einrichtung einer unabhängigen Regierung und dem Abzug der Besatzungstruppen zu erwarten. Auch darin schien die schon zuvor gelegentlich angedeutete Überlegung, daß die Deutschen noch nicht die demokratische "Reife" zeigten, die ihre Entlassung in die Selbständigkeit erlauben würde, nun in das Gegenteil der von R\&A stets vertretenen Ansicht umzuschlagen, denn R\&A hatte immer dafür plädiert, daß die Militärregierung nur für einen möglichst kurzen Zeitraum aufrechterhalten werden sollte. Während R\&A aber stets bezweifelt hatte, daß Deutschland durch ein Besatzungsregime erfolgreich demokratisiert werden könne, hatte man damals noch gehofft, daß es genügen würde, gewisse Grundvoraussetzungen für eine Demokratisierung zu schaffen, deren Vollendung man dann den Deutschen selbst überlassen können würde.

Doch die Nachkriegsentwicklungen hatten fast alle Befürchtungen, aber keine der Hoffnungen der Abteilung Wahrheit werden lassen: Die Aufteilung Deutschlands in Besatzungszonen zeitigte all die negativen Konsequenzen, die man in R\&A vorausgesagt hatte; wie man befürchtet hatte, ließ die Militärregierung die Entwicklung einer autochthonen demokratischen Bewegung in Deutschland nicht zu, erstickte die freilich nur zaghaften Ansätze zu der von R\&A für so unverzichtbar gehaltenen „social revolution“ und scheiterte in ihren eigenen Bemühungen um eine „artificial revolution“. Wie die R\&A-Nachfolgeorganisationen im State Department aufzeichneten, war letzteres freilich nicht nur der Unfähigkeit der amerikanischen Militärregierung oder der Inkompetenz der Washingtoner „decision makers" zuzuschreiben: So wenig Unterstützung die demokratischen Gruppen in Deutschland von der Militärregierung erhalten hatten, so wenig vielversprechend schien auch ihr eigenes demokratisches Potential. Angesichts der politischen Haltung der Deutschen mochte man sich so in OIR -

${ }^{97}$ NA, RG 59, OIR/(R\&A) 4929, 15.6. 1949, deutsch bei Söllner (Hrsg.), Archäologie der Demokratie, Bd.2, S. 286-310.

98 Vgl. dazu auch Neumanns Bemerkungen in seinem 1948 erschienenen Artikel Militärregierung und Wiederbelebung der Demokratie, in: ders., Wirtschaft, Staat, Demokratie, S. $309 \mathrm{f}$. 
mit Horkheimers Mitarbeiter Gurland - fragen, „[if the ] sorry outcome of four years of attempted democratization [...] would [...] have been different if the occupying powers had left the re-establishment of democracy in Germany to German democrat-

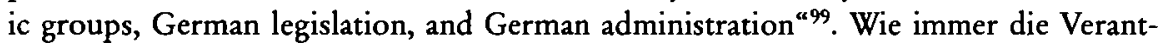
wortung für das nach Ansicht von OIR offenbare Scheitern der Demokratisierung Deutschlands zu verteilen war, mußte die Entlassung der Deutschen in die - wenn auch noch eingeschränkte Selbständigkeit - vier Jahre nach Kriegsende als verfrüht erscheinen, denn die von den Besatzern geschaffenen demokratischen Institutionen schienen noch immer nur "auf Sand gebaut“, so daß „selbst ein kleineres Erdbeben [...] sie zu Fall bringen" mochte ${ }^{100}$.

Berücksichtigt man die sich über mehr als zwei Jahre erstreckende Ausprägung dieser Überzeugung und die ihr als Maßstab zugrundeliegenden, noch während der Kriegsjahre von R\&A entwickelten Konzeptionen, so scheint es nicht gerechtfertigt, der OIR-Analyse zum deutschen Nationalismus "beinahe paranoide Züge" zuzuschreiben oder zu behaupten, daß in ihr "fast schon verschwörungstheoretisch, eine Strategie der ewig Gestrigen" unterstellt würde ${ }^{101}$. Wie Söllner ausführt, mußte die OIR-Analyse angesichts der Ergebnisse der zwei Monate später abgehaltenen ersten deutschen Bundestagswahl als völlig verfehlt erscheinen. Da aber ein solch massives Fehlurteil angesichts der Fach- und Sachkompetenz der OIR-Mitarbeiter kaum vorstellbar sei, vermutet Söllner hinter diesem „Fehlurteil“ wiederum eine politische Strategie: „... den amerikanischen Deutschlandpolitikern soll durch die Ausmalung des schlimmst-möglichen Scenarios jede Naivität und jeder voreilige Optimismus genommen werden; gleichzeitig soll die Aufmerksamkeit vor allem der amerikanischen Konservativen von der Fixierung auf den Ost-West-Konflikt ab-und auf das wichtiger scheinende Problem eines grassierenden deutschen Nationalismus hingelenkt werden." 102

Doch abgesehen davon, daß sich die in der OIR-Analyse zum deutschen Nationalismus vertretenen Positionen weniger abrupt von den in anderen Arbeiten der Abteilung vorgetragenen Beurteilungen abheben, als Söllner annimmt, stand OIR mit dieser scheinbaren „Paranoia" keineswegs allein. Um nur ein Beispiel zu nennen: In einer Analyse der „Political Trends in Western Germany“, die die neu gegründete Central Intelligence Agenćy (CIA) im Juli 1948 vorlegte $^{103}$, war festgestellt worden: „The

99 Gurland, Why Democracy is Losing in Germany, in: Commentary 8/3, September 1949, S.227-237. Gurland bot in diesem Artikel eine ausgezeichnete Analyse; seine Berücksichtigung der sozialpsychologischen Verfassung der „Zusammenbruchgesellschaft" erlaubte es $\mathrm{ihm}$, den deutschen Nationalismus differenzierter und nüchterner einzuschätzen, als OIR es konnte. Die These, daß die amerikanische Besatzungspolitik letztlich nur geringfügigen Einfluß auf die politischen und gesellschaftlichen Entwicklungen hatte, hat später Peterson am entschiedensten vertreten: The American Occupation of Germany.

100 So Holborn in seinem „Bericht zur deutschen Frage“ im Januar 1948, in: VfZ 35 (1987), S. 156.

101 Söllner (Hrsg.), Archäologie der Demokratie, Bd.2, S. 251 ff.

102 Ebenda, S.253f.

${ }^{103}$ Truman/PSF-CIA/MF II, 0356: ORE 52-48, CIA, 22.7. 1948. Ähnliche Beurteilungen finden sich - außer in den im folgenden noch erörterten Studien - z. B. in dem in Anmerkung 100 zitierten Bericht Holborns. Aufschlußreich auch die Klage Marion Dönhoffs über die große Aufmerksamkeit, die dem deutschen Nationalismus in US-Medien zuteil wurde, in dies., Germany Puts Freedom before Unity, Foreign Affairs, April 1950, S.398-411. 
East-West tensions in Germany [.. .] threaten to destroy Western German adherence to moderate political groups and to stiffen resistance to Western Allied policy. The US stand against Communism is being interpreted as tacit permission for a revival of German nationalism. " 104 Wie wenig sich die in dieser Analyse vertretenen Positionen insgesamt von denen OIRs unterschieden, mag hier ein ausführlicheres Zitat illustrieren:

„The present polarization of Western German thought toward political extremes is influenced by the following three basic indigenous factors: (1) growing dissatisfaction with the occupation and with the weak German governmental administrations identified with it; (2) the probability of the future disintegration of the moderate Social Democratic Party, the only strong non-Communist labor force in Germany; and (3) the rightist trend of general German political desires which has increased as a result of the large enfranchisement of ex-Nazis. In the course of this polarization, the Social Democrats may lose political strength to both the Right and the Left, while the alignment of the rightist parties will be affected by the strong current of resurgent German nationalism. [...] The trend as a whole may result in the diminution of the moderate parties, the development of a small but aggressive Left, and the expansion of the Right with increasing Western German independence of Allied controls. "

Aufschlußreich ist, daß diese pessimistischen Beurteilungen weder OIR noch das Office of Research and Estimates (ORE) der CIA daran hinderten, das Ergebnis der ersten deutschen Bundestagswahl im wesentlichen richtig vorauszusagen. OIR ließ allerdings in dem Ende Juli erscheinenden Bericht über den Wahlkampf keine Gelegenheit aus, um anzudeuten ${ }^{105}$, daß das voraussichtlich formal-demokratisch befriedigende Wahlergebnis nicht darüber hinwegtäuschen dürfe, daß sich die deutsche Demokratie immer noch als bloße Episode erweisen könnte.

Nach Darstellung von OIR gestaltete sich der Wahlkampf für die erste Bundestagswahl am 14. August 1949 eher schwerfällig, was auf die Apathie der Wählerschaft und die Finanzknappheit der Parteien zurückzuführen sei ${ }^{106}$. Die Mehrheit der Wähler erwarte sich vom Wahlausgang keinerlei bedeutsame Veränderungen in der Politik, sondern gehe davon aus, daß sich die neue Bundesregierung bei der Lösung der zentralen wirtschaftlichen und sozialen Probleme weiterhin auf die Westalliierten, insbesondere die USA, stützen und von ihnen abhängig sein würde. Gleichzeitig sei aber eine deutlich ausgeprägte Empfänglichkeit für jegliche Propaganda zu beobachten, die sich gegen die Einmischung fremder Mächte in deutsche Angelegenheite richte.

$\mathrm{Da}$ alle Parteien um die Gunst von Wählern aus einer weitgehend einheitlichen sozialen Schicht konkurrierten, wiesen die Parteiprogramme große Ähnlichkeiten auf. Die meisten Programme wandten sich zentralen Problemen wie Wohnungsbauprogrammen, Arbeitsplätzen und Sonderfonds für Flüchtlinge sowie Fragen sozialer Sicherheit zu und betonten daneben die wichtigsten nationale Forderungen wie die Einstellung von Demontagen, eine Senkung der Besatzungskosten, die Vereinigung Deutschlands und die Rückgabe der Ostgebiete. Zwischen der SPD und den beiden

104 Im Dokument von Hand unterstrichen.

105 NA, RG 59, OIR/R\&A) 5014, „Election Campaign and Prospective Results in the New West German State ${ }^{\alpha}, 25.7 .1949$.

106 Ganz anders die Darstellung bei Benz, Von der Besatzungsherrschaft zur Bundesrepublik, S. $251 \mathrm{ff}$, der einen recht hitzigen Wahlkampf beschreibt. 
bürgerlichen Parteien, der CDU und den Liberalen, konzentriere sich die Auseinandersetzung auf die Diskussion der Vor- und Nachteile von wirtschaftlichem Liberalismus und Planwirtschaft.

Die CDU könne im Wahlkampf in hohem Maße auf die "moralische Unterstützung" des katholischen Klerus rechnen und genieße überdies, wie auch die Liberalen, die traditionelle finanzielle Unterstützung der privaten Industrie. Die SPD dagegen sähe sich aufgrund der offiziell geltenden Neutralität der Gewerkschaften eines Teils ihrer traditionellen Unterstützung beraubt.

Das Wahlgesetz, das OIR als "hybrid“ charakterisierte - und das "more the outcome of political horsetrading between the CDU and SPD than of a search for an ideal election pattern" sei -, kombiniere Mehrheitswahlrecht und Verhältniswahlrecht, begünstige die großen etablierten Parteien sowie diejenigen kleineren Parteien, die, wie etwa die Bayernpartei oder die Deutsche Partei, über starke regionale Anhängerschaft verfügten. Es sei insbesondere von Flüchtlingsorganisationen scharf angegriffen worden, $\mathrm{da}$ es, zusammen mit Verordnungen der Militärregierung, praktisch verhindere, daß sich Kandidaten aus diesen Gruppen unabhängig zur Wahl stellten.

Bei der Prognostizierung des Wahlergebnisses orientierte sich OIR an den Vorkriegswahlen sowie den seit Kriegsende abgehaltenen Landtagswahlen ${ }^{107}$. Nach Ansicht der Abteilung war mit einer Wahlbeteiligung zwischen 70 und 80 Prozent zu rechnen; aufgrund des durchgängig hohen Anteils an ungültigen Stimmen in allen Nachkriegswahlen - nämlich zwischen sechs und sieben Prozent der abgegebenen Stimmen, im Gegensatz zu weniger als einem Prozent vor 1933 - sei ein entsprechend hoher Anteil ungültiger Stimmen auch bei der Bundestagswahl zu erwarten. In ihnen manifestierte sich nach Ansicht der Abteilung "the existence of a certain hard-core opposition to the new regime" - und, wie hinzugefügt wurde: "given the opportunity, this element might in future elections support ultra-nationalist groups". Insgesamt glaubte OIR so, den Prognosen zum Wahlausgang die einschränkende Bemerkung voranstellen zu müssen: „Owing to the mechanics of the election law, the licensing rules of Military Government, and the hesitation of many potential nationalist leaders to enter the political arena at this early stage, the elections, whatever their results, will not reveal the full force of the extreme right." Vorausgesagt wurde, daß die radikale Rechte sowie die Kommunisten im ersten Bundestag numerisch schwach sein würden. Die Abteilung hielt eine parlamentarische Mehrheit einer einzelnen Partei für unwahrscheinlich, glaubte allerdings, daß die SPD einen höheren Stimmenanteil als die CDU gewinnen würde. Konkret erwartete OIR, daß auf die SPD etwa 34\% der Stimmen entfallen würden, während für CDU und Zentrum mit einem Stimmenanteil von 25$26 \%$ gerechnet wurde; das bedeute, daß beide Parteien zusammen über etwa zwei Drittel der Sitze verfügen würden.

Angesichts dieses Wahlergebnisses werde die erste Bundesregierung eine Koalitionsregierung sein; entweder könnte sie von SPD und CDU gebildet werden oder aber von CDU und Liberalen sowie einigen der kleineren konservativen Parteien des bürgerlichen Lagers. Es sei zu erwarten, daß die erstgenannte Kombination im

107 Vgl. dazu auch NA, RG 59, OIR/(R\&A) 4861, „Local Elections in Western Germany and Berlin October - December 1948“, 23.2. 1949. 
Bundestag über eine „komfortable“ Zwei-Drittel-Mehrheit verfügen und insofern in der Lage sein würde, eine parlamentarisch stabile Regierung zu bilden. Eine nach der zweiten Kombinationsmöglichkeit gebildete Regierung - als „anti-Socialist coalition" apostrophiert - würde dagegen nur über eine knappere Stimmenmehrheit verfügen und sich von Anfang an heftiger Opposition sowohl von seiten der Linken als auch der extremen Rechten ausgesetzt sehen. OIR erwartete, daß eine solche Koalition, ähnlich wie das Direktorium des bizonalen Wirtschaftsrats, dazu tendieren würde, "to rely heavily on so-called politically neutral expert ministers"; für administrative und legislative Maßnahmen wäre diese Koalition wegen ihrer knappen Mehrheit im Bundestag in hohem Maße auf die Unterstützung des Bundesrats angewiesen.

Wiederum stimmten die von OIR vertretenen Positionen weitgehend mit denen der Kollegen von der CIA überein. Sie hatten schon eine Woche vor OIR die "Probable Consequences of the Forthcoming West German Elections"108 skizziert und ebenfalls vorausgesagt, daß CDU/CSU und SPD zusammen mindestens 60 Prozent der Stimmen erhalten würden, daß aber keine der beiden Parteien für sich allein über eine Mehrheit verfügen würde. So sah auch ORE zwei mögliche Koalitionen, nämlich CDU/CSU und SPD, eventuell mit einer Beteiligung der FDP, oder aber eine Koalition aus CDU/CSU, FDP und den kleineren Parteien der Rechten. ORE ließ keinen Zweifel daran, welche der beiden Möglichkeiten vorzuziehen sei: „Of the two coalitions, a CDU/CSU-SPD coalition would be the more favorable to US interests because of its control of the Federal Diet, its greater stability, its more progressive composition, and its firmness toward the Communists. The alternative coalition would be far less favorable to US interests because it: (a) would be less stable, (b) would face far more powerful parliamentary opposition, (c) would be of a more rightist complexion - thus evoking the opposition of organized labor - and (d) would be more likely to seek the reunification of Germany with Soviet support."

Das Plädoyer der CIA-Abteilung für eine Regierungsbeteiligung der SPD und die in diesem Zusammenhang vorgetragenen Argumente illustrieren, daß es nicht gerechtfertigt wäre, die von OIR vertretenen Positionen als Ausnahmeerscheinung innerhalb einer Nuancen gegenüber blinden, nur noch „rot“ sehenden US-Administration zu interpretieren ${ }^{109}$. Die CIA-Studie erreichte immerhin den Schreibtisch des Präsidenten der freilich weder am Ausgang der ersten deutschen Bundestagswahl noch an der folgenden Regierungsbildung viel ändern konnte.

Die "Effects of the Election in Western Germany “110 analysierte OIR dann in einer Ende August vorgelegten Studie, in der das Aufkommen eines neuen deutschen Nationalismus weitgehend unerwähnt blieb. Wenn auch wenig enthusiastisch, konzedierte die Abteilung: "Those groups which stand unconditionally for the reconstruction of Western Germany on Western democratic patterns, i.e., the SPD and the CDU/CSU have a clear majority of 60 percent, and with the FDP of over 70 percent of the total

108 Truman/PSF-CIA/MF II, 0369: CIA, ORE 67-49, 19.7. 1949.

109 Vgl. dazu auch oben VII., 1. Teil.

110 NA, RG 59, OIR/(R\&A) 5024, „Analysis and Effects of the Election in Western Germany“, 31.8. 1949. 
vote cast." Wie OIR ausführte, seien diese Parteien zwar durch das Wahlsystem eindeutig begünstigt worden, doch hätte auch ein reines Verhältniswahlrecht die wesentliche Verteilung der Stimmen mit ihrer Mehrheit für CDU/CSU und FDP gegenüber den Sozialdemokraten nicht verändert.

Während die Kommunisten sowohl absolut gesehen an Stimmen und noch mehr an Prozenten der Gesamtstimmen verloren hätten, hätten die beiden großen Parteien jeweils etwa eine Million Stimmen hinzugewonnen. Angesichts des durch Erstwähler und Flüchtlinge verursachten Wähleranstiegs von sieben Millionen hätten beide Parteien aber gemessen in Prozenten der abgegebenen Stimmen Anteile verloren. Nach Ansicht von OIR erklärte sich dies vor allem dadurch, daß viele Flüchtlinge für die FDP sowie die kleineren Parteien der Rechten und unabhängige Kandidaten gestimmt hätten; für die CDU/CSU falle auch die Bildung der Bayernpartei und der Deutschen Partei sowie ein Ausfall an protestantischen Wählerstimmen ins Gewicht. Insgesamt sei der Anteil der SPD und KPD an den Gesamtstimmen mit etwa 36 Prozent seit 1928 ungefähr gleich geblieben.

Unklar war jedoch nach Ansicht der Abteilung, „[if] the election [has] really given a clear anti-Socialist mandate to the future Bundestag, as the defenders of Dr. Erhard's economic policy assert". Da der Wahlkampf nicht in erster Linie um die Frage der künftigen wirtschaftlichen Verfassung ausgefochten worden sei, sei auch nicht anzunehmen, daß der neue Bundestag diese Frage als zentrales politisches Problem betrachten würde. Die Abteilung glaubte davon ausgehen zu können, „[that] the Bundestag will be pressed by many groups both from among its components and from without, and issues will be fought and compromises concluded according to the need and strength of the groups concerned". Über das Ergebnis dieses Prozesses konnte nach Ansicht von OIR nur spekuliert werden.

In drei wesentlichen Punkten ließ das Wahlergebnis nach Ansicht der Abteilung aber eindeutig die Richtung der künftigen Politik erkennen. So hätten die Gewerkschaften nun deutlich verringerte Aussichten, wirtschaftliche Mitbestimmung - insbesondere auf der über das einzelne Unternehmen hinausgehenden Ebene - als Recht für ganz Westdeutschland festgeschrieben zu haben; dasselbe gelte für Sozialisierungspläne auf westdeutscher Ebene, obwohl offen sei, inwieweit die Länder in der Lage sein würden, entsprechende Gesetze zu erlassen, da derartige Maßnahmen von der CDU/CSU entweder durch geeignete Bundesgesetzgebung oder durch ihren Einfluß in den Landesregierungen blockiert werden könnten. Eine weitere Frage, die durch das Wahlergebnis entschieden worden sei, habe im Wahlkampf zwar keine große Rolle gespielt, sei aber dennoch von Bedeutung: Die Stimmenmehrheit für CDU/CSU und FDP die in dieser Frage zudem die Unterstützung der Mehrheit rechter Gruppen haben würden - bedeute ,the definite return to pre-eminence of the higher bureaucracy and the casting aside of the more democratized type of civil service system that had been begun under MG auspices“. Davon abgesehen sei damit zu rechnen, daß sich das Verhältnis zwischen Westdeutschen und Alliierten nicht gundsätzlich ändern werde, auch wenn jede Regierung gezwungen sein würde, deutsche Interessen gegenüber fremden Mächten mit Nachdruck zu verfechten. Die klare Absage an den Kommunismus und die Tatsache, daß im Bundestag keine starke extreme Rechte vertreten sei, würde sowohl die Arbeit der deutschen Regierung wie der alliierten Hochkommissare erleichtern. 
Eine pessimistische Perspektive war in dieser Analyse nur dann erkennbar, wenn man sie im Kontext der in anderen OIR-Arbeiten vertretenen Positionen las ${ }^{111}$. Ansonsten wurde hier das Bild einer formal funktionierenden, aber mitnichten über eine stabile Basis verfügenden Demokratie gezeichnet, deren Zukunftsperspektiven ungewiß erschienen, zumal sie nach Darstellung von OIR letztlich doch eindeutig autoritäre und reaktionäre Tendenzen zeigte ${ }^{112}$. Ihre Entlassung in die - wenn auch noch eingeschränkte - Selbständigkeit wurde hier nicht problematisiert, andererseits wurde aber auch kein $Z$ weifel daran gelassen, daß dieses schwer erziehbare „Ziehkind“ unverzüglich, energisch und notfalls auch rücksichtslos versuchen würde, seine eigenen Interessen gegenüber seinen „Ziehvätern" durchzusetzen.

Als Bündnispartner des Westens galt die junge Bundesrepublik dann auch noch bis in die fünfziger Jahre hinein als unsicherer Kandidat - und zwar gerade wegen des immer besorgt beobachteten Nationalismus und wegen weitverbreiteter tiefsitzender Zweifel an ihrer demokratischen Standfestigkeit. Ein entsprechend prekäres Bild vermittelte beispielsweise eine Ende 1949 fertiggestellte CIA-Studie, die sich relativ ausführlich mit der „deutschen Frage “ beschäftigte ${ }^{113}$. Ähnlich wie in R\&A-Studien wurde einleitend zunächst der geschichtliche Hintergrund der aktuellen Situation skizziert, wobei herausgestellt wurde, daß sich seit der zweiten Hälfte des 19. Jahrhunderts in Deutschland ein System ausgebildet habe, in dem die Macht dem preußischen Militär, den Junkern und den Großindustriellen gehörte, deren gehorsamstes Instrument eine „vast bureaucracy“ gewesen sei. Zentralismus und politischer Autoritarismus hätten so eine starke Tradition in Deutschland, und zudem seien die Deutschen seit 1871 immer mehr nationalistisch "indoktriniert" worden.

So sei den Bemühungen der Westmächte um die Stärkung föderalistischer und antinationalistischer Tendenzen und Kreise nur begrenzter Erfolg beschieden gewesen: "Centralism and nationalism remain nonetheless predominant in the outlook of the average German and will become increasingly active forces as control over their own destiny is returned to the Germans“. Auch die Autoritätshörigkeit der Deutschen sei noch immer stark ausgeprägt; so sei man der von den Westmächten initiierten Rekonstruktion demokratischer politischer Strukturen zunächst nur „lukewarm or passively receptive" begegnet, und noch in den Länderverfassungen zeige sich „the ingrained German predilection for granting extensive power to leaders“. Vor diesem Hintergrund hielt man den Abzug der Besatzungstruppen nicht für ratsam: „There is danger [...] that already existing anti-democratic and nationalist tendencies will be streng-

${ }^{111}$ Während andere Stellen - wie im folgenden noch illustriert wird - die Entwicklung eines neuen Nationalismus noch bis in die fünziger Jahre hinein fürchteten, scheint man sich in OIR seit Ende 1949 mit diesbezüglichen Prognosen zurückgehalten zu haben; entsprechend nüchtern und weitgehend deskriptiv NA, RG 59, OIR/(R\&A) 5176, „Western German Political Splinter Groups“, 11.5. 1950.

112 Eine in diesem Zusammenhang interessante Analyse findet sich in NA, RG 59, OIR/(R\&A) 5334, "The Composition of The German Bundestag, 1950“, 25.9. 1950; vgl. zu diesem Themenkreis auch Herz, German Officialdom Revisited, in: World Politics 7/1, October 1954, S. 63-83; und ders., Denazification and Related Policies, in: ders. (Hrsg.), From Dictatorship to Democracy, S.15-38, besonders 30ff.; sowie Edinger, Post-Totalitarian Leadership, in: The American Political Science Review LIV (März 1960), S.58-82, und Benz, Versuche zur Reform des öffentlichen Dienstes, in: VfZ 29 (1981), S. 216-245.

${ }^{113}$ Truman/PSF-CIA/MF II, 0255: CIA, „Germany“, SR-20, 9.12. 1949. 
thened [...] The existence of the present western German Government might ultimately be jeopardized by the attitude of nationalistic elements seeking to achieve their objectives through collusion with the USSR. “114

Noch Mitte 1950 beobachtete man die innere Entwicklung der Bundesrepublik nicht ohne Besorgnis ${ }^{115}$. Ein Bericht des US-Hochkommissariats beschäftigte sich 1954 eingehend mit den Tendenzen der Adenauer'schen Kanzlerdemokratie „towards a moderate authoritarian government in which the executive is the dominant branch of the government“. Die demokratischen Kräfte in Westdeutschland hätten keine tiefen Wurzeln und, so wurde festgestellt: „Many of the elements which made possible the rise of extremism in Germany are still present.“ Dabei sei insbesondere an die „longings and frustrations of the middle classes " zu denken, die letztlich allerdings eher als potentielle denn akute Gefahr eingeschätzt wurden, denn man glaubte annehmen zu können, daß die konkrete Erfahrung des Nationalsozialismus viele Deutsche gegen Experimente mit politischen Extremen immunisiert habe. Dennoch wurde nicht ausgeschlossen, $\mathrm{da}$ sich die bisher erkennbaren autoritären Tendenzen der westdeutschen Kanzlerdemokratie unter ungünstigsten Umständen, insbesondere im Falle einer wirtschaftlichen Stagnation, bedenklich verstärken könnten.

Mit ihrer pessimistischen Beurteilung der westdeutschen Demokratie standen die im State Department verbliebenen R\&A-Deutschlandexperten so keineswegs alleine. $\mathrm{Ob}$ sich Franz Neumanns These, daß die Westmächte in Deutschland aufgrund ihrer „falschen Theorie der Demokratie“ nur „demokratische Prozeduren“ installiert, aber keine Basis für eine lebensfähige Demokratie gelegt hätten ${ }^{116}$, letztlich bestätigen würde, schien damit bis in die fünfziger Jahre hinein noch offen. Doch wie Neumann in anderem Zusammenhang selbst einmal angemerkt hatte, kann „die Wissenschaft der Politik“ eine solche Frage „nicht entscheiden - die Entscheidung fällt die Geschichte" ${ }^{\text {"117. }}$

114 Ähnliche Schlußfolgerungen in Truman/PSF-CIA/MF II, 0377: CIA, ORE 1-50, „Political Orientation of the West German State“, 25.4. 1950, wo zwar für die nächsten Jahre - zumindest bis etwa 1953 - eine im wesentlichen westliche Ausrichtung der Bundesrepublik erwartet wird, gleichzeitig aber auch starke Kräfte zugunsten eines neutralen Deutschlands beschrieben werden und eine Schwächung bzw. Destabilisierung der Regierung Adenauer durch ein Erstarken der Rechten nicht ausgeschlossen wird.

${ }^{115}$ „Some Observations on West German Political Developments“, U.S. HICOG, Bonn to The Department of State, Washington, dokumentiert von Schröder, Die Anfangsjahre der Bundesrepublik Deutschland, in: VfZ 37/2 (1989), S.323-351.

116 Neumann, Militärregierung und Wiederbelebung der Demokratie in Deutschland (1948), in: ders., Wirtschaft, Staat, Demokratie, S. 309-325.

117 Neumann, Die Wissenschaft der Politik in der Demokratie (1950), in: ders., Wirtschaft, Staat, Demokratie, S. 392. 